\title{
The introduction of forgiveness into a path analytical model of the association between parental divorce and adult attachment
}

Amanda L. Wheat

West Virginia University

Follow this and additional works at: https://researchrepository.wvu.edu/etd

\section{Recommended Citation}

Wheat, Amanda L., "The introduction of forgiveness into a path analytical model of the association between parental divorce and adult attachment" (2009). Graduate Theses, Dissertations, and Problem Reports. 2788.

https://researchrepository.wvu.edu/etd/2788

This Thesis is protected by copyright and/or related rights. It has been brought to you by the The Research Repository @ WVU with permission from the rights-holder(s). You are free to use this Thesis in any way that is permitted by the copyright and related rights legislation that applies to your use. For other uses you must obtain permission from the rights-holder(s) directly, unless additional rights are indicated by a Creative Commons license in the record and/ or on the work itself. This Thesis has been accepted for inclusion in WVU Graduate Theses, Dissertations, and Problem Reports collection by an authorized administrator of The Research Repository @ WVU. For more information, please contact researchrepository@mail.wvu.edu. 
The Introduction of Forgiveness into a Path Analytical Model of the Association between Parental Divorce and Adult Attachment

Amanda L. Wheat

Thesis submitted to the Eberly College of Arts and Sciences

at West Virginia University

in partial fulfillment of the requirements

for the degree of

\author{
Master of Science \\ in \\ Psychology
}

\author{
Kevin Larkin, Ph.D., Chair \\ Steven Branstetter, Ph.D. \\ Julie Patrick, Ph.D. \\ Department of Psychology \\ Morgantown, West Virginia \\ 2009
}




\begin{abstract}
The Introduction of Forgiveness into a Path Analytical Model of the Association between Parental Divorce and Adult Attachment
\end{abstract}

\title{
Amanda L. Wheat
}

Several factors (i.e., parental divorce, parent-child relationship quality, interparental conflict, individual forgiveness) that have been investigated separately in relation to adult romantic attachment were examined alongside family forgiveness, which has not previously explored in relation to attachment. Undergraduate students $(\mathrm{N}=299)$ completed several surveys online for the current study. Several significant findings emerged when factors were considered in path models individually, and in an overall path model built on the basis of those individual model findings. Maternal and paternal social support, maternal negative interactions, and family forgiveness were moderators of parental divorce - romantic attachment relations. Based upon these findings, it was concluded that (1) several factors should be accounted for beyond parental divorce when considering the link between parental marital status and romantic attachment in young adulthood, and (2) family and individual forgiveness, which have not been studied as extensively as other factors in the relevant literature, should also be included in future investigations of romantic attachment. 


\section{Table of Contents}

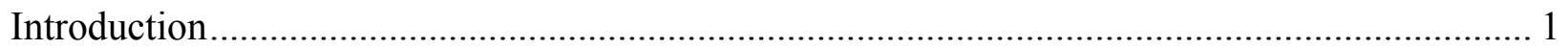

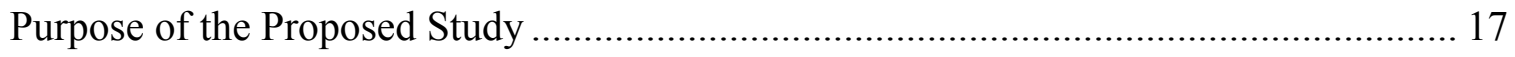

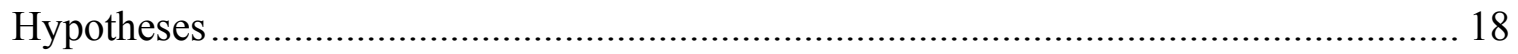

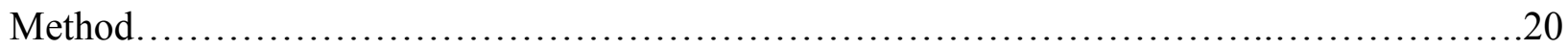

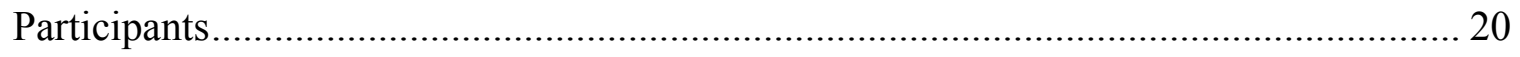

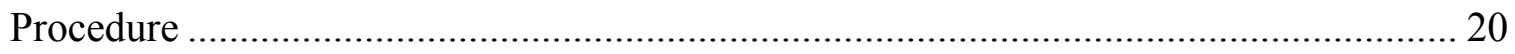

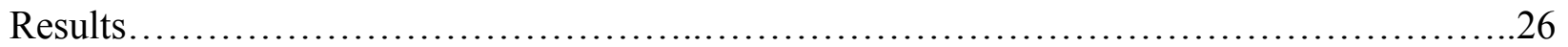

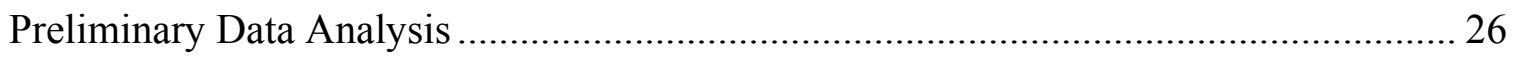

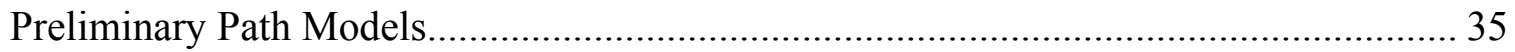

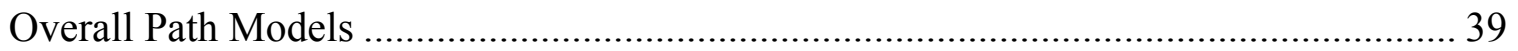

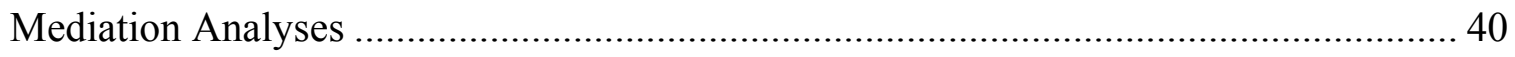

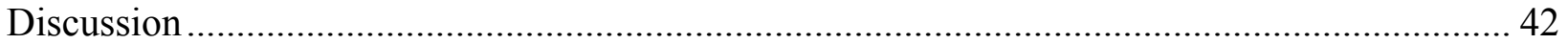

Parent-Child Relationship Quality and Attachment .............................................. 44

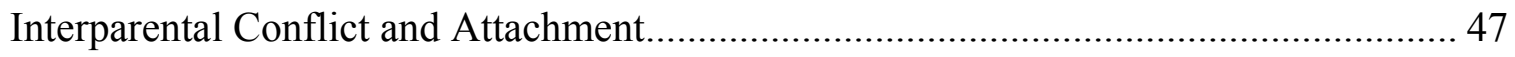

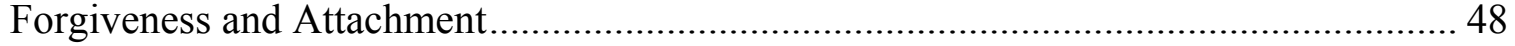

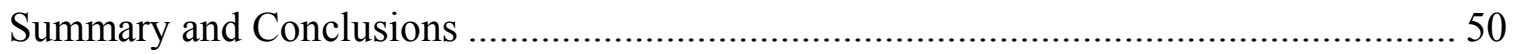

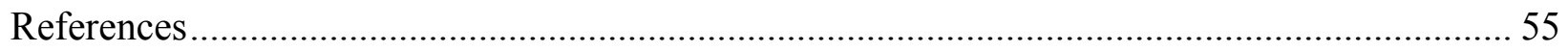

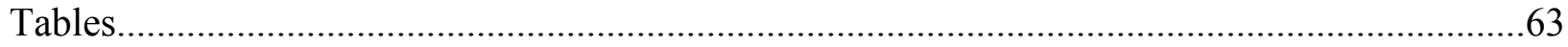

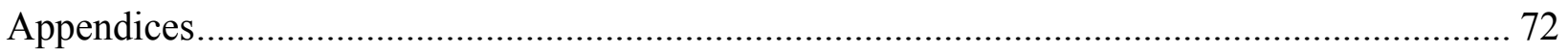




\section{Introduction}

Divorce peaked in the late 1970s and early 1980s and has exhibited a decreasing trend since that time, but the marital climate in the United States continues to be dismal (Bramlett \& Mosher, 2002). In their most recent report on family growth, The National Center for Health Statistics (NCHS) indicated that one third of marriages end in divorce or separation after ten years of marriage. More recent data analyzed by NCHS shows that divorces occur at a rate of 3.6 per 1,000 of the population (Eldridge \& Sutton, 2007). Much attention has been given to not only the effects of divorce for those who experience it firsthand, but also for those who are exposed to it without choice.

Within the last few decades, attendance to the effects of parental divorce and how individuals whose parents divorced differed from those whose families remained intact has increased. Parental divorce has been linked to psychopathology, employment, academic achievement, problems with substance use, and behavior problems, among other factors (e.g., Amato \& Sobolewski, 2001; D’Onofrio et al., 2007; Lansford, Malone, \& Castellino, 2006). Additionally, several aspects involved in romantic relationships of offspring have received considerable attention over the past few decades, particularly in relation to parental marital status. Wallerstein (1991) asserted that “...the long-term...consequences [of parental divorce] emerge developmentally on center stage when the young person is at the threshold of adulthood and contemplates the major life decisions of love, commitment, and marriage" (p. 354). Such endeavors prove difficult to navigate for some adults who experienced parental divorce earlier in life, as evidenced by support for the idea that divorce is transmitted from one generation to the next. Conservative appraisals estimate that children who experience parental divorce are 50\% more likely to have their own marriages end in divorce when compared to those whose parents' 
marriages remain intact (Segrin, Taylor, \& Altman, 2005). Some data, however, indicate that the increased likelihood of divorce is much greater, with individuals from divorced households being $123 \%$ more likely to divorce than their counterparts from intact households (Amato \& Cheadle, 2005). Persons from divorced households are also more likely to experience multiple divorces than those whose parents maintained intact marital relationships (Ross \& Mirowsky, 1999).

Such information has led to the theory of intergenerational transmission of divorce (Bramlett \& Mosher, 2002; Emery, 1999), which is a phenomenon that may be due to several factors. For example, it has been shown that children from divorced households have difficulties successfully managing conflict in their adult romantic relationships, likely because their parents modeled deficient skills in managing, or failing to manage, their own marital conflict (Emery, 1999). In general, those who withstand parental divorce, when compared to persons from intact homes, marry earlier, exhibit more negative attitudes toward marriage, and have unhappier marriages (Amato \& Cheadle, 2005; Roberts, 2000; Ross \& Mirowsky, 1999). Given these potentially negative influences on developing and maintaining successful committed relationships later in life, it is important to consider factors surrounding parental divorce that affect the children in the family and to explain how divorce influences these children's subsequent relationships in such a negative fashion.

One of the earliest foci of research exploring the deleterious effects of parental divorce was attachment security. A presupposition that several investigators had at the time, which would later be supported empirically, was that divorce could rupture interpersonal bonds in the family. These ruptures clearly occurred within the divorcing couple, but researchers also proposed that these problems could extend to the parent-child relationship, possibly engendering insecure attachment in children. As results were published over the past few decades, however, it 
became clear that the association between parental divorce and attachment was multifarious.

Some researchers found support for the proposed link between parental divorce and insecure attachment while other investigators failed to find that individuals from divorced families were less securely attached than those from intact families. Consequently, several factors presumably related to divorce (i.e., parent-child relationship quality and interparental conflict) became the subject of investigation into the relation between parental divorce and attachment security.

Several studies have provided support for the links between attachment and both parentchild relationship quality and interparental conflict. However, few have explicitly assessed how either factor could mitigate the association between parental divorce and attachment in future romantic relationships. This study is therefore proposed to directly address the ability of parentchild relationship quality and marital conflict to modify the relation between parental divorce and attachment security in adulthood. Moving beyond previously executed investigations, it is also proposed that an individual's history of family forgiveness and current propensity for forgiveness should be examined to further elucidate the complicated relation between parental divorce and security of attachment in adults. Data have suggested that children exhibit levels of forgiveness similar to their parents (Mullet, Girard, \& Bakhshl, 2004; Mullet, Riviere, \& Munoz Sastare, 2006; Neal, 2006; Subkoviak et al, 1995), indicating that forgiveness may be learned from familial interactions. A few investigations have also shown that securely attached persons exhibit higher levels of forgiveness than persons with insecure interpersonal attachment patterns (e.g., Burnette, Taylor, Worthington, \& Forsyth, 2007; Lawler-Row, Younger, Piferi, \& Jones, 2006; Mikulincer \& Goodman, 2006; Webb, Call, Chickering, Colburn, \& Heisler, 2006), an interpersonal process that is clearly important in maintenance of committed romantic relationships during adulthood. Therefore, how one's family approached forgiveness as they 
were raised may be an important factor to consider in dissecting the relation between parental marital status and attachment security in subsequent romantic relationships; how one consequently forgives in adulthood (i.e., individual/participant forgiveness) should remain a variable of interest in relation to romantic attachment security during adulthood as well. Such analyses will aid in understanding how parental divorce is linked to the development and maintenance (i.e., attachment security and individual forgiveness) of relationships in adulthood, and how such development and maintenance is informed by historical interactions in the family of origin (i.e., parent-child relationship quality, interparental conflict, and family forgiveness). After reviewing attachment security and the research attempting to characterize the association between it and parental divorce, the additional proposed variables of interest, and what is currently known regarding their relation to parental divorce and/or attachment, will be addressed in the following discourse.

\section{Attachment}

Several decades ago, Bowlby $(1980 \mathrm{a} ; 1980 \mathrm{~b} ; 1980 \mathrm{c})$ postulated that the nature of interactions between child and caregiver result in a specific style of attachment exhibited by the child and that these interactions and consequent attachment style set the stage for patterns of behavior in relationships with others throughout the lifespan. If an attachment figure interacts warmly with the child and is consistently available and responsive to the child, the resulting style of attachment may be described as secure. Conversely, if the attachment figure is unavailable, unreliable, or unresponsive to the child's needs and desires, the attachment of child to caregiver assumes an insecure quality.

The first to extend Bowlby's theory in an extensive laboratory study, Ainsworth, Blehar, Waters, and Wall (1978) delineated three categories of attachment based on behavioral 
observations between children and their mothers. One category was labeled secure attachment. The remaining two categories, anxious/ambivalent and avoidant attachments, were variant topographies of insecure attachment styles.

In more recent research on attachment, investigators became interested in attachment beyond the parent-child relationship. Romantic attachment was soon recognized as an important extension of historical attachment literature because romantic relationships play an important role in late adolescence and emerging adulthood. Arnett (2002) discusses how emerging adulthood involves a rather chaotic period of new life experiences. Individuals aged 18-25 years are often faced with living outside their parental household for the first time, assuming partial or full financial responsibility, managing qualitatively different peer and romantic relationships, and other tasks. Though some shifts occur beginning in adolescence (i.e., transient dating experiences), emerging adulthood is the true period of growth and transformation according to Arnett. Romantic attachment may be particularly important at this time for two reasons. First, having healthy and supportive attachments to romantic partners may serve to facilitate transitions in other rapidly changing arenas. Second, exploration of romantic relationships during that time serves to inform individuals of their expectations of themselves and others within the context of these relationships. Arnett refers to the latter as part of role identification that occurs during emerging adulthood. Acknowledging the importance of romantic attachment, while realizing it may bear similarity to attachment between parents and children, romantic attachment was conceptualized initially along the same three dimensions as in Ainsworth and her colleagues' (1978) work (Hazan \& Shaver, 1987). Eventually, however, it was measured in such a way that, instead of a unidimensional classification, an attachment profile could be produced indicating to what extent an individual is secure, dismissive, preoccupied, and fearful in their adult romantic 
relationships (Bartholomew \& Horowitz, 1991). All currently and historically used measures of attachment, however, are grounded in Bowlby's original theory of attachment security in addition to Ainsworth et al.'s behaviorally based contributions.

The development of a particular attachment style establishes in the child working models of how relationships function, including their relationships with caregivers during development and, later in life, with romantic partners. Therefore, those who have experiences with available and responsive caregivers during childhood, and develop secure attachments as a result, tend to approach later relationships in life with comfort and trust (Hazan \& Shaver, 1987). Conversely, individuals who are subjected to unavailable or unresponsive caregivers early in life will typically be insecure in approaching romantic relationships in adulthood, often exhibiting fear, anxiety, and distrust.

It is thereby unsurprising that parental divorce, which often involves unstable or dysfunctional marital and parent-child relationships, has been investigated as a precursor to insecure attachment style. Erel and Burman (1995) performed a meta-analysis to determine if support existed for the spillover hypothesis, which prescribes that a positive marital climate will result in positive parent-child relationships while negative marital interactions precipitate poor parent-child relationships. As expected, quality of the marital relationship 'spilled over' into the quality of the parent-child relationship. Turmoil within the married dyad co-occurred with deficiencies in the parent-child relationship. Therefore, because attachment theory dedicates utmost importance to the relationship between caregiver and child, it is understandable that investigators began to look at divorce, an event typically precipitated by poor marital quality, as a probable associate of insecure attachment in relationships throughout childhood and adulthood. 
Though most researchers have not grounded their investigations on the spillover hypothesis, many have investigated the association between parental divorce and attachment insecurity based on similar logic. Even Bowlby (1980b), without directly referencing the event of divorce, wrote that "...there is the anxiety engendered in a child when he overhears his parents quarrelling and fear, not unnaturally, that one or the other of them is going to leave" (Bowlby, 1980b, p. 227). Results from investigations linking divorce with insecure attachment, however, are mixed.

Some studies have shown that, for both men and women, parental divorce is associated with parental or romantic attachment insecurity as indexed in adulthood (Brennan \& Shaver, 1998; Kilmann, Carranza, \& Vendemia 2006; Lewis, Feiring, \& Rosenthal, 2000; Summers, Forehand, Armistead \& Tannenbaum, 1998; Waters, Merrick, Treboux, Crowell, \& Albersheim, 2000). Concerning parental attachment at 18 years of age, Lewis et al. (2000) found that men and women from divorced households were more likely to be insecurely attached while those from intact parental marriages were more likely to be securely attached. Another study longitudinally assessed the relation between attachment at one year and 18 years of age with stressful life events, including parental divorce (Waters et al, 2000). The likelihood of an individual's parental attachment changing from a secure attachment style in infancy to an insecure attachment in adulthood was higher for those who experienced stressful life events, including parental divorce, between the two measurement periods. Such a pattern did not emerge for those who were initially classified as insecurely attached. Kilmann and associates (2006) investigated the association between parental divorce and romantic attachment in adulthood using a female sample, and they also found marital status of parents to be associated with attachment in adulthood, with women from intact families reporting more secure attachments than those with 
divorced parents. Summers and his colleagues' (1998) analyses indicated that men and women from divorced parents were less likely to exhibit secure romantic attachments than persons from parents with intact marriages. Finally, security of romantic attachments in adulthood has also been significantly predicted by parental marital status in men and women (Brennan \& Shaver, 1998).

Other studies have found that the relation between parental divorce and attachment style depends on child and/or parent sex, albeit in differing directions. For example, Riggio (2004) assessed the relation between parental divorce and attachment to parents in adulthood. In this study, parental attachment was considered to be composed of affective quality, emotional support, and facilitated independence, as all three related to each parent when evaluated separately. Men from divorced households, in contrast to men from intact homes, reported lower affective quality and emotional support when rating paternal attachment. Significant differences between women from intact and divorced parents, however, were not observed for any of the three attachment components. Conversely, Barber (1998) found that parental marital status predicted romantic attachment style in adulthood for women, though this relation was not apparent for men.

Still other investigators have failed to find a significant association between parental divorce and parental or romantic attachment style in adulthood for either men or women (Brennan \& Shaver, 1993; Hazan \& Shaver, 1987; Hazelton, Lancee, \& O’Neil, 1998; LawlerRow et al, 2006; Lopez, Melendez, \& Rice, 2000). In brief, although there is some evidence that growing up in a family in which parents divorce threatens secure attachment, divorce clearly does not uniformly affect attachment security of all children with divorcing parents. 


\section{Parent-Child Relationship Quality}

Researchers reasoned that the relation between parental marital status and attachment was reflected inconsistently in the data because other factors were influencing attachment security more directly and reliably. For example, a number of investigators began to look beyond parental marital status in predicting attachment deficits in adulthood by assessing the impact of interparental conflict and diminished parent-child relationship quality, which have both been shown to co-occur with divorce, as associates of attachment pattern (Amato \& Booth, 1997; Amato \& Cheadle, 2005; Booth \& Amato, 2001; Hanson, 1999; Killman et al., 2006; Lopez et al., 2000; Riggio, 2004; Ruschena, Prior, Sanson, \& Smart, 2005; Sobolewski \& Amato, 2007). The logical shift from the examination of parental divorce as a precursor of attachment insecurity to analyzing parent-child relationship quality as a potential contributor to attachment security was made. The redirection of attention to parent-child relationships was germane because the association between parental marital status and attachment security was sometimes found (Brennan \& Shaver, 1998; Kilmann et al., 2006; Lewis et al., 2000; Summers et al., 1998; Waters et al., 2000), indicating the importance of family processes in determining attachment security, and due to the documented link between divorce and parent-child relationship quality (Amato \& Booth, 1996; Amato \& Sobolewski, 2001; Booth \& Amato, 1994; Mack, 2001; Riggio, 2004; Roberts, 2000; Sun, 2001).

Early attachment theory proposed that the association between parent-child relationship quality and attachment is interactive; less responsive mothers could yield 'differential development' in the child's attachment style, which could in turn affect the mother's behavior, and so on (Bowlby, 1980c). When implementing this theory in the lab using the strange situation scenario, Ainsworth and her co-investigators (1978) found support for Bowlby's assertions via a 
significant relation between strange situation performance and quality of non-analogue interactions between the mother and child. Consistent with Bowlby's assertions and later support from Ainsworth and Hazan and Shaver (1987), the important role parent-child relationship quality might play in the child's attachment style when developing intimate relationships was acknowledged. Though Hazan and Shaver did not find support for the link between parental divorce and attachment style in adulthood, their data revealed that one of the best predictors of adult attachment style was the quality of the relationship between parent and child, as reported retrospectively by the offspring.

More recent studies have yielded results similar to those found by Hazan and Shaver (1987). Brennan and Shaver (1998) found that insecurely attached individuals described their relationships with their parents as less accepting than did securely attached individuals. Hazelton et al. (1998) also found that, regardless of parental marital status, participants who reported having more rejecting parents were more likely to be insecurely attached. Though it did not significantly mediate the relation between parental divorce and attachment security, Summers and his collaborators (1998) found father-child relationship quality to be a significant predictor of attachment in adulthood. Killman et al. (2006) also found interesting results that varied by parent sex in their solely female sample. Securely attached women rated their fathers' parenting characteristics more positively than did their insecurely attached counterparts. In another study, several aspects of the parent-child relationship, such as level of parental care or overprotection, were found to predict avoidance and anxiety of adult attachment for White men and women from both intact and divorced families (Lopez et al., 2000). For Hispanic/Latino and Black participants, attachment-related anxiety was significantly predicted by parent-child bond, though attachment-related avoidance was not predicted by parent-child bond. These results 
comprehensively illustrate that attachment security is partly contingent on the quality of the relationship between the child and his or her parent(s).

\section{Interparental Conflict}

As shown in the previous section, investigators moved away from divorce per se, and toward examining the effects of parent-child relationship quality on attachment security. A similar approach was taken in exploring the association between interparental conflict and attachment security. Because the link between parental divorce and attachment insecurity proved significant in a number of incidences, investigators thought it rational to examine relationship factors that were known associates of parental marital status, but that may be more proximally related to attachment security. Due to their established associations with parental divorce (Hanson, 1999; Roberts, 2000; Segrin, Taylor, \& Altman, 2005; Tayler, Parker, \& Roy, 1995), interparental conflict and parental marital quality, which often includes an index of conflict, were studied in relation to attachment security.

As previously noted, Hazan and Shaver (1987) reported that parent-child relationship quality predicted attachment security. Results were similar for marital quality as indexed by affection, care, and happiness within the parents' marriage. They found these characteristics to be the 'best discriminators' between secure and insecure participants; insecurely attached individuals reported that their parents' marriages were of lower quality than securely attached individuals. Brennan and Shaver's (1993) findings concurred, with higher likelihood of insecure attachments co-occurring with unhappy parental marriages. Notably, there was no increased or decreased likelihood of insecure attachments among children of parents who were happily married. 
Marital conflict has been shown to be related to attachment insecurity in individuals from divorced and intact families (Roberts, 2000). Kenny and Donaldson (1991) analyzed attachment security and marital conflict and found that individuals with less secure attachments reported higher levels of conflict between their parents. Davies, Harold, Geoke-Morey, and Cummings (2002) also found support for the negative association between attachment security and interparental conflict. That relation was mediated by parenting difficulties indicative of poor parent-child relationship quality (e.g., deficient parental warmth). They also examined the content of interparental conflict and discovered that children exhibited more negative emotional responses during an analog argument when it was related to family dissolution or to the child, compared to arguments involving other issues.

Investigators have indicated the importance of studying interparental conflict due to the differential effects divorce can effectuate on psychological well-being (e.g., psychological distress and relationship satisfaction) depending on the level or nature of conflict that parents exhibit in their marital relationship (Amato, Loomis, \& Booth, 1995; Booth \& Amato, 2001). Children from high-conflict families tend to exhibit higher levels of well-being if the parents divorce rather than persist in marriage, while children from low-conflict families usually report lower levels of well-being if their parents separate than if they stay together. Therefore, though parent-child relationship quality may be a direct predictor of insecure attachment (e.g., Davies et al., 2002), it is clear that interparental conflict should also be considered when examining relationship difficulties, including insecurity of attachment, among young adults. Further investigations would also be useful in delineating whether interparental conflict is reliably responsible for moderating the relation between parental marital status and attachment security in romantic adult relationships. 


\section{Family and Individual Forgiveness}

Considering that interparental conflict is associated with insecure attachment in offspring, it is important to consider how conflict is resolved within both the marital dyad and the entire family unit because offspring are believed to learn interpersonal behaviors, including conflict management skills, from observing and experiencing relevant interactions within the family (Amato, 1996; Mullet et al., 2004; Noller, Feeney, \& Sheehan, 2000). A key component of successful conflict resolution is forgiveness. In assessing the content of numerous therapeutic interventions fostering forgiveness, Wade and Worthington (2005) reconcile the relevant definitions of forgiveness utilized in these interventions into a comprehensive definition: “...forgiveness is a positive method of coping with a hurt or offense that primarily benefits the victim through a reorientation of emotions, thoughts, and/or actions toward the offender" (p. 160). They also stipulate that forgiveness entails reduction in negative feelings, such as bitterness and anger (i.e., 'unforgiveness'), alongside increases in positive feelings, such as love, sympathy, or pity, relative to the transgressor. They further assert that forgiveness does not necessarily involve reconciling with the offender(s), or excusing, condoning, or tolerating the transgression. Conceptualized in this way, forgiveness is clearly important in maintaining romantic relationships in adulthood. One must be able to cope with conflict resulting from transgressions by his or her partner in an effective way, by increasing positive and decreasing negative emotions, so that the problems do not perseverate and the relationship can grow healthier if reconciliation does occur. In brief, deficiencies in forgiveness skills may ultimately translate into deficiencies in conflict resolution and romantic relationship maintenance.

One study recently examined forgiveness (as characterized by benevolence, avoidance, and retaliation) and conflict resolution in married couples (Fincham, Beach, \& Davila, 2004). 
Concerning wives' forgiveness, results revealed that conflict resolution was rated as more effective when benevolence was higher. Regarding husbands' forgiveness, effective conflict resolution was associated with low avoidance and retaliation. In total, the results suggested a significant association between conflict resolution and forgiveness in the expected direction.

The importance of parents' ability to resolve conflict through forgiveness becomes even clearer when considering that parental forgiveness has been shown to be associated with offspring forgiveness (Hoyt, Fincham, McCullough, Maio, \& Davila, 2005; Maio, Fincham, Thomas, \& Carnelley, 2008; Mullet et al., 2004; Mullet et al., 2006; Neal, 2006; Subkoviak et al., 1995), confirming the aforementioned belief that the family is an important context in which children learn interpersonal skills, such as conflict resolution. The natural implication of these findings when considered together is that low forgiveness in parents may lead to low forgiveness and poor conflict resolution in the immediate context of the family, and eventually in the more distal context of their children's relationships.

Concerning children's later romantic relationships, forgiveness has been shown to be related to security of attachment (Blount-Matthews, 2005; Burnette et al., 2007; Crawley, 2006; Davidson, 2001; Hanford, 2006; Lawler-Row et al., 2006; Luebbert, 2000; Mikulincer \& Goodman, 2006; Webb et al., 2006). For example, Lawler-Row et al., (2006) showed that both measures of state and trait forgiveness were associated with romantic attachment security in adults. Those classified as insecurely attached had lower trait forgiveness than securely attached participants. Insecurely attached persons also reported lower levels of state forgiveness than their secure counterparts. Reports from insecurely attached persons additionally demonstrated that they foresaw wanting to avoid the offender more than securely attached persons after future transgressions. The authors extrapolated that this could predispose those who are securely 
attached to persist in their relationships during conflict, allowing a greater likelihood of forgiveness occurring. In noting the practical significance of these results, the investigators explained, “The history of one's [attachment] relationships and their security may have an impact on the resiliency of current relationships, especially in the face of conflict and betrayal" (p. 493). It is consequently possible that insecure attachment, through its association with low levels of forgiveness, impedes the ability to successfully navigate conflict with one's romantic partner. Considering in tandem that insecurely attached individuals have historically reported more interparental conflict, that parents exhibiting high conflict are thought to model poor conflict resolution, and that children learn from their parents' styles of conflict and forgiveness, individuals who are insecurely attached may be at a severe disadvantage concerning the potential ability to maintain stable romantic relationships.

As has been illustrated, individuals who experience parental divorce, or associated poor parent-child relationship quality and interparental conflict, tend to develop insecure attachment styles. It may then be argued that the associations between parental divorce (or poor parent-child relationship quality and interparental conflict) and insecure attachment styles may be explained through low family or individual forgiveness and conflict resolution skills. In other words, offspring for whom family forgiveness was low may exhibit low forgiveness in adulthood, which would presumably impact the stability of their romantic relationships; the interplay of family and individual forgiveness in addition to parent-child relationship quality and interparental conflict may provide a comprehensive purview of the mechanisms through which the relation between parental divorce and attachment security is moderated. This likelihood appears more imminent considering the implications of divorce, parental marital conflict, and poor parental marital quality put forth by several researchers. Similar to the intergenerational transmission of divorce, 
Amato and Booth (1997) noted that poor marital quality is reported more often by those whose parents had marriages of poor quality. They specifically found in an earlier investigation that individuals from divorced or unhappily intact homes reported more marital conflict or problems than those from happily intact households (Amato \& Booth, 1991). Emery (1999) purported that one of the main mechanisms through which the intergenerational transmission of divorce is thought to occur is deficiency in resolving conflict due to modeling inefficient behaviors witnessed in their parents. In extending other authors' extrapolations, it may be that children from divorced households (Lawler-Row et al., 2006) or from parents with low levels of forgiveness (Hoyt et al., 2005; Mullet et al., 2004; Mullet et al., 2006; Noller et al., 2000; Subkoviak et al., 1995) exhibit relatively low levels of forgiveness and meet consequent difficulties in romantic relationships because proficient forgiveness skills were not modeled by their parents or inculcated via broader familial interactions.

In comprehensively analyzing the statistical evidence and its associated implications offered by several authors, it is clear that the seemingly unreliable association between parental divorce and attachment security in adult romantic relationships may be explained by the more proximal relations between attachment security and both parent-child relationship quality and interparental conflict, each having been linked with divorce. Finally, though forgiveness has been illustrated as an associate of attachment security, family and individual forgiveness have not been directly assessed as factors of import to consider in the potential link between parental divorce and attachment insecurity, precluding a more comprehensive understanding of how parental divorce may lead to relationship difficulties. 


\section{Purpose of the Proposed Study}

According to the experimental literature described, parental divorce may be directly or indirectly associated with the ability to develop and maintain romantic adult relationships via its associations with parent-child relationship quality, interparental conflict, family forgiveness, individual/participant forgiveness, and attachment security. Because poor quality and unsatisfactory romantic relationships in adulthood have been associated with diminished psychological and physical well-being, parental divorce may serve as an efficient clinical indicator of those who may be at heightened risk for psychological or mental health problems stemming from their relationship difficulties. Therefore, it is imperative that the nature of the pathways between parental divorce, parent-child relationship quality, interparental conflict, parental marital quality, family and individual forgiveness, and attachment security be clarified. Such clarification will make possible the identification of individuals from divorced families who may or may not be particularly predisposed to problematic romantic relationships in adulthood. Further, the ability of parental divorce, or its associated psychological effects, to serve as indicators for mental health risks may be determined.

As evidenced by the preceding review, some links between parental divorce, interparental conflict, parental marital quality, parent-child relationship quality, attachment security, forgiveness, and adult romantic relationship quality have been established (e.g., Amato \& Cheadle, 2005; Emery, 1999; Lawler-Row et al., 2006; Lewis et al., 2000; Riggio, 2004; Sobolewski \& Amato, 2007), but these links have not been fully elucidated. No study to date has explored the associations among these psychological variables in a single sample. This gap in knowledge necessitates a closer examination of the interrelations among these variables when considered as a comprehensive network. 
The purpose of this study is to rectify this gap by simultaneously assessing factors related to families of origin (parental marital status, quality of parent-child relationship, interparental conflict, family forgiveness) and current relationship development and maintenance skills (attachment security and individual forgiveness). In doing so, replication of several previous studies will occur through exploration of co-relations among parental marital status, parent-child relationship quality, and interparental conflict. More importantly, current knowledge will be expanded by clarifying how these factors interact with one another-and with family and individual forgiveness - to explain the intergenerational transmission of inadequate relationship building and maintenance skills. It may then be understood how an individual's familial and interpersonal history relates to forgiveness and attachment security, and thereby to adult relationship quality.

\section{Hypotheses}

The path diagram pictured below (Figure 1) is representative of the proposed path analytical model and all relevant individual hypothesized paths. Each square represents a single observed variable, and each arrow indicates a proposed significant path between variables.

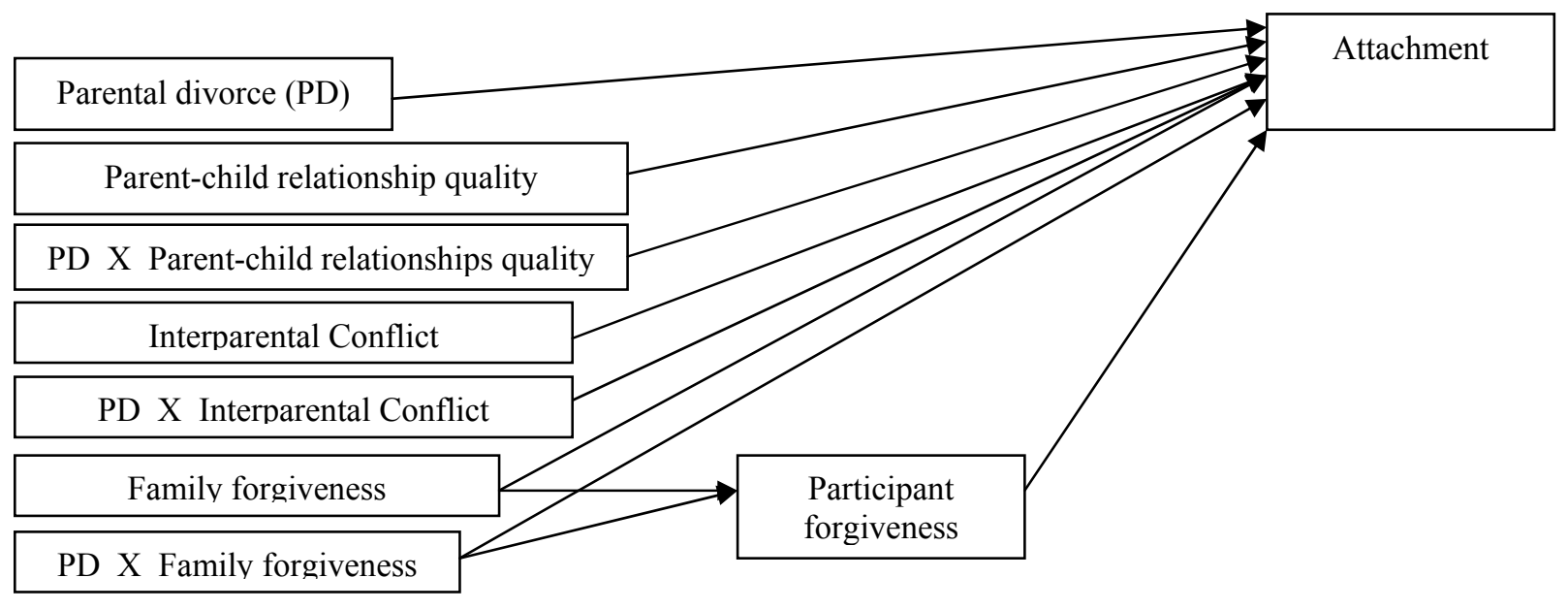

Figure 1. Hypothesized overall path model. 
Prior to analyzing the overall model, each intermediate variable was assessed in relation to parental divorce and romantic attachment. Those variables which proved to be significant in predicting romantic attachment in adulthood were entered into the comprehensive path model as projected above:

1. Parent-child relationship quality: It was hypothesized that the relation between parental divorce and romantic attachment would be significantly moderated by parent-child relationship quality.

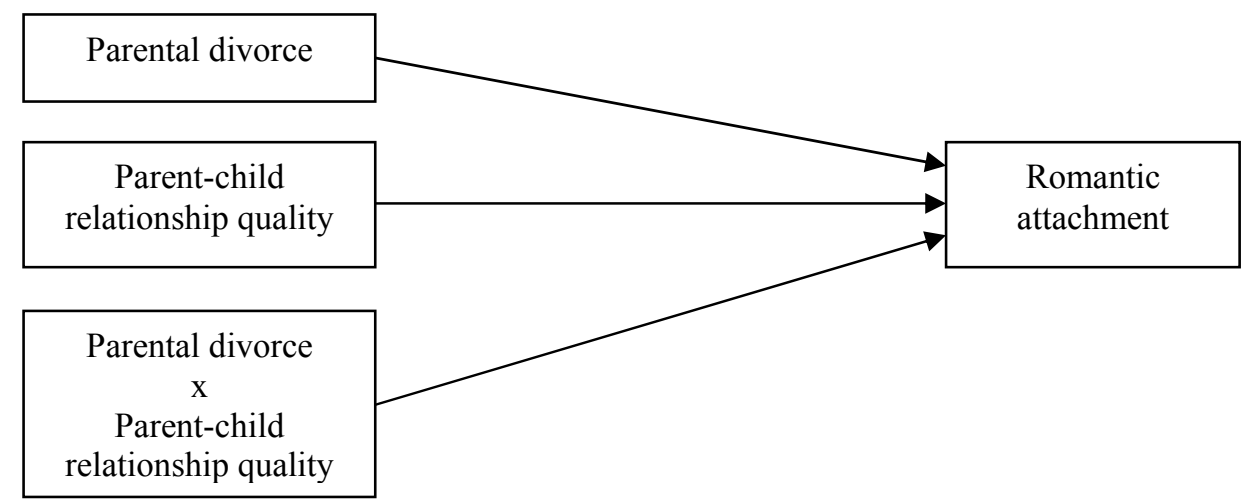

Figure 2. Hypothesized relations between parental divorce and romantic attachment as moderated by parent-child relationship quality.

2. Interparental conflict: It was hypothesized that interparental conflict would significantly moderate the relation between parental divorce and romantic attachment.

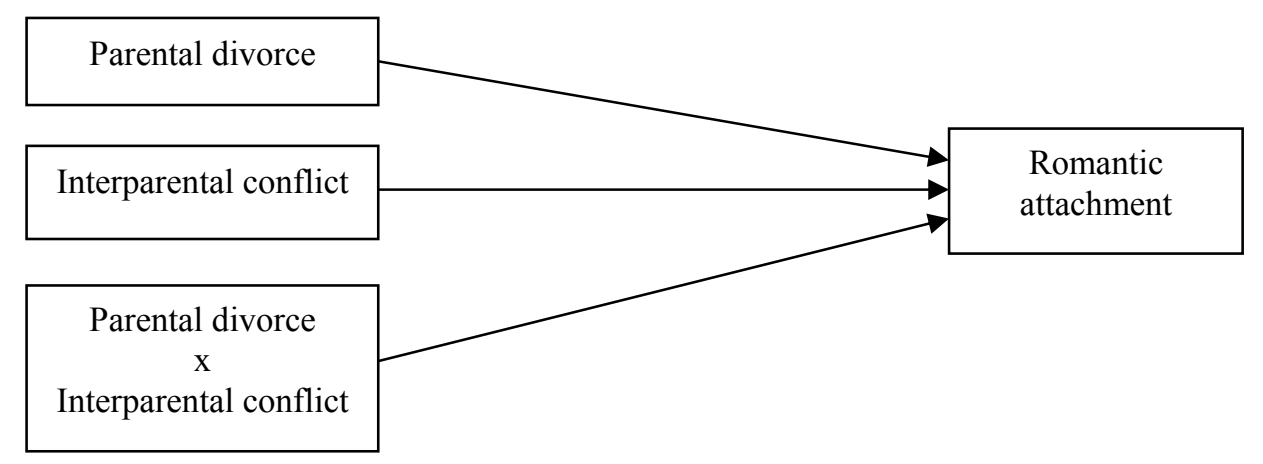

Figure3. Hypothesized relations between parental divorce and romantic attachment as moderated by interparental conflict. 
3. Family forgiveness:

a. It was hypothesized that the association between parental divorce and romantic attachment would be significantly moderated by family forgiveness.

b. It was hypothesized that family forgiveness would significantly predict participant forgiveness, which would in turn be significantly associated with romantic attachment.

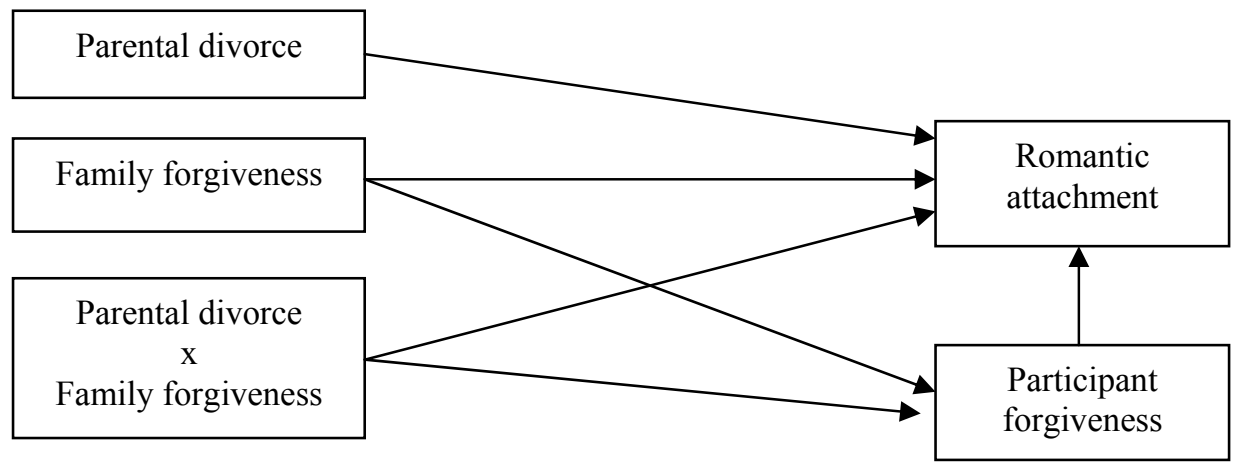

Figure 4. Hypothesized relations between parental divorce and romantic attachment as moderated by family forgiveness and modified by participant forgiveness.

Method

\section{Participants}

Three-hundred-forty-three students enrolled in Psychology courses participated in the current study. No active recruitment methods were utilized aside from making the study available on the World Wide Web via the SONA system. Students interested in participating in research signed into the system and were able to read a description of the study and participate if desired.

Procedure

Participants completed all proposed measures through the SONA system at their convenience. Therefore, no constraints were placed on participants concerning time or location required to complete the study. As compensation for participation, participants received either 
extra credit or regular course credit, dependent upon the Psychology course in which they were enrolled.

Self-Report Measures

Demographics and Parental Divorce. Standard demographic inquiries regarding sex, age, SES-related information, etc. were included in the current questionnaire (Appendix A). Participants indicated whether their biological parents are divorced or intact. Participants also responded to questions assessing if divorce(s) or remarriage(s) occurred during several age ranges between birth and the time at which they participated in the current study. Participants were categorized as having experienced parental divorce if one or more divorces occurred during any of the listed age ranges. Participants who reported their parents to be married at the time of their participation in the study were categorized as having intact parents.

Adult Romantic Attachment. Attachment was measured with the Behavioral Systems Questionnaire (BSQ) (W. Furman, personal communication, November 21, 2007). The BSQ contains separate sections based on relationship type (e.g., parent, friend), but the content across these sections is similar. Further, the following behavioral systems are assessed for each relationship type: attachment, caregiving, affiliation, and physical intimacy/sexuality. Though participants completed 60 questions across the four behavioral systems listed for romantic relationships, the focus of the current study were 15 questions assessing attachment within romantic relationships. Participants were instructed to respond to the questions based on how they typically act and feel in their romantic relationships, including present and past experiences. Responses were given on a 5-point Likert-type scale of agreement/disagreement $(1=$ strongly disagree, 5 = strongly agree), yielding average Secure, Dismissing, and Preoccupied attachment scores for each participant. Cronbach's alpha was sufficient for Secure (.89), Dismissing (.85), 
and Preoccupied (.84) Attachment scores. Table 1 contains possible and actual score ranges for the BSQ, as well as for the measures discussed below.

Table 1. Descriptive properties of self-report measures.

\begin{tabular}{|c|c|c|c|c|}
\hline Measure & $\begin{array}{l}\text { Possible Item } \\
\text { Score Range }\end{array}$ & $\begin{array}{l}\text { Sample } \\
\text { Average } \\
\text { Item Score } \\
\text { Range }\end{array}$ & Mean & SD \\
\hline \multicolumn{5}{|c|}{ Parent-child Relationship Quality (NRI) } \\
\hline - Maternal Social Support & $1-5$ & $1.48-5$ & 3.77 & .69 \\
\hline - Maternal Neg. Interaction & $1-5$ & $1-5$ & 2.18 & .86 \\
\hline - Paternal Social Support & $1-5$ & $1-5$ & 3.30 & .81 \\
\hline - Paternal Neg. Interaction & $1-5$ & $1-4.83$ & 1.95 & .86 \\
\hline \multicolumn{5}{|l|}{ Interparental Conflict (CPICS) } \\
\hline - Conflict Properties & $1-3$ & $1-3$ & 1.72 & .50 \\
\hline - Threat & $1-3$ & $1-3$ & 1.68 & .46 \\
\hline - $\quad$ Self-Blame & $1-3$ & $1-2.44$ & 1.24 & .33 \\
\hline \multicolumn{5}{|l|}{ Forgiveness } \\
\hline$\bullet \quad \mathrm{FFQ}$ & $-24-24$ & $-19-24$ & 13.28 & 9.09 \\
\hline$\bullet \quad$ FPI & $33-165$ & $65-165$ & 122.21 & 19.02 \\
\hline \multicolumn{5}{|l|}{ Attachment (from the BSQ) } \\
\hline - Secure Attachment & $1-5$ & $1-5$ & 3.81 & .76 \\
\hline - Dismissing Attachment & $1-5$ & $1-5$ & 2.49 & .81 \\
\hline - $\quad$ Preoccupied Attachment & $1-5$ & $1-5$ & 2.34 & .80 \\
\hline
\end{tabular}

Parent-Child Relationship Quality. The Network of Relationships Inventory (NRI) (W.

Furman, personal communication, November 21, 2007) was used to assess parent-child relationship quality. An earlier version of the NRI exhibited adequate internal consistency when used with fifth- and sixth-grade girls and boys, with an average Cronbach's alpha value of .80 (Furman \& Buhrmester, 1985). Across 30 total items, ten subscales are available on the most recent version of the NRI: companionship, conflict, instrumental aid, antagonism, intimacy, nurturance, affection, admiration, relative power, and reliable alliance. Broader subscales of social support and negative interaction may also be derived from obtaining the average of certain 
subscales as well, which were the scores analyzed in the current study. Although the NRI is suitable for assessment of several types of relationships (e.g., sibling, peer), only parent-child relationship quality was of interest in the current study. Therefore, participants responded to 30 items both for male and female parental figures they previously identified in the demographics questionnaire as being their primary parental figures. Responses were made according to a 5point Likert-type scale ranging either from "little or none" to "the most" (e.g., How much do you and this person get on each other's nerves?) or from "(s)he always does" to "I always do" (e.g., Who tells the other person what to do more often, you or this person?). Average scores were calculated separately for mothers and fathers, yielding two social support and two negative interaction scores. Due to an error in question entry into the SONA system, 3 items were omitted from this study's analyses. However, none of these items were utilized in the indexes of social support or negative interaction, so analyses were not considered to be effected by their exclusion.

For the current data, Cronbach alpha values were as follows: Maternal Social Support (.93), Paternal Social Support (.95), Maternal Negative Interaction (.59), Paternal Negative Interaction (.62). Although internal consistency reliability was good for measures of parental support, they were less adequate for measures of negative interaction.

Interparental Conflict. A modified version of Grych, Seid, and Fincham's (1992) Children's Perception of Interparental Conflict Scale (CPICS) was used to assess interparental conflict for all participants in the current sample (Appendix B). The scale was originally developed for use with children and was piloted with samples of children ranging in age from nine to twelve years. The CPICS measures how children view and interpret the conflict exhibited by their parents in respect to 9 facets: frequency, resolution, intensity, content, perceived threat, coping efficacy, self-blame, triangulation, and stability. Respondents rate forty-eight items as 
being true, sort of true, or false in reference to their parents' conflict along these dimensions. These components were distributed among three derived subscales, namely Conflict Properties (frequency, resolution, intensity), Threat (perceived threat, coping efficacy), and Self-Blame (self-blame, content). In the original study, internal consistency was shown to be acceptable for all three subscales. Conflict properties exhibited alpha coefficients of .89 to .90 . The alpha coefficient for the Threat subscale was .83. The Self-Blame subscale also had sufficient internal consistency, as evidenced by alpha coefficients ranging from .78 to .84. Test-retest reliability was also of an acceptable level for Conflict Properties, Threat, and Self-Blame subscales, with correlations between administrations being .70, .68 , and .76 respectively. Grych et al. also reported sufficient concurrent validity by comparing the CPICS with established parent reports of marital conflict.

Bickham and Fiese (1997) administered the CPICS to individuals aged 17-21 years to discern whether it was a valid measure for an older population. Their data revealed a factor structure similar to that found with the original school-aged sample. Reliability and validity were also similarly acceptable in the late adolescent sample. The CPICS has also been modified for age appropriateness and used successfully elsewhere with late adolescents and young adults (Mann \& Gilliom, 2004; Roberts, 2000).

Average scores were calculated for Conflict Properties, Threat, and Self-Blame subscales, and these average scores were utilized to represent interparental conflict in the current sample. Chronbach alpha values were sufficient in the current sample for Conflict Properties (.95), Threat (.87), and Self-Blame (.83) subscales.

Family Forgiveness. Maio et al.'s (2008) Family Forgiveness Questionnaire (FFQ) was utilized in the current study (Appendix C). It consists of two elements, one measuring tendency 
to forgive others and the other assessing perceptions of forgiveness from others within one's family. The scale was originally constructed using several family members' responses to the FFQ, among other scales. The portion of the FFQ measuring the tendency to forgive other family members was utilized in the proposed study. In the original study, alpha reliabilities for this component of the FFQ were calculated for each dyad scale (i.e., daughter forgives mother), and all met or exceeded .87 . Test-retest measurements correlated significantly with each other, with correlations ranging from .53 to .74 .

Maio et al. (2008) constructed the measure so that participants were prompted to "remember times that the target family member offended them by doing things that could not be easily understood or excused" before answering 8 items assessing tendencies to forgive that family member. The FFQ was modified in the proposed study to provide a more general, situation-independent, and retrospective measure of family forgiveness. Participants were not prompted to recall a specific time their mother or father transgressed against them, and items were reworded so they were in past tense. All items (e.g., "I held grudges against him") were preceded by the prompt, “Generally, when I or my family members annoyed, hurt, or offended each other as I was growing up ...”; the original rating scale utilized by Maio et al. remained intact, and agreement with each item was rated on a 7-point Likert scale ranging from -3 (strongly disagree) to 3 (strongly agree). Total FFQ scores were analyzed for this study, and Cronbach's alpha was of sufficient magnitude (.92).

Individual/Participant Forgiveness. The Forgiving Personality Inventory (FPI), as developed by Drinnon, Jones, and Lawler (as cited in Lawler-Row et al., 2006) was used to assess participant forgiveness in this study. The scale is comprised of 33 items that comprehensively reflect how forgiving an individual is across situations. All items are rated on a 
5-point agreement/disagreement Likert scale ( $1=$ Strongly Disagree, $5=$ Strongly Agree $)$.

Historically reported internal validity (.93) and test-retest reliability (.86) of the FPI are both of sufficient magnitude. Total participant forgiveness scores were calculated and subject to analyses for the current investigation. Cronbach's alpha for the FPI in the current sample was .95 .

\section{Results}

\section{Preliminary Data Analysis}

In preparation for conducting the primary analyses, data were imported from the SONA data acquisition system into SPSS v16.0. As depicted in Figure 5, 343 individuals provided consent and initiated participation in the study.

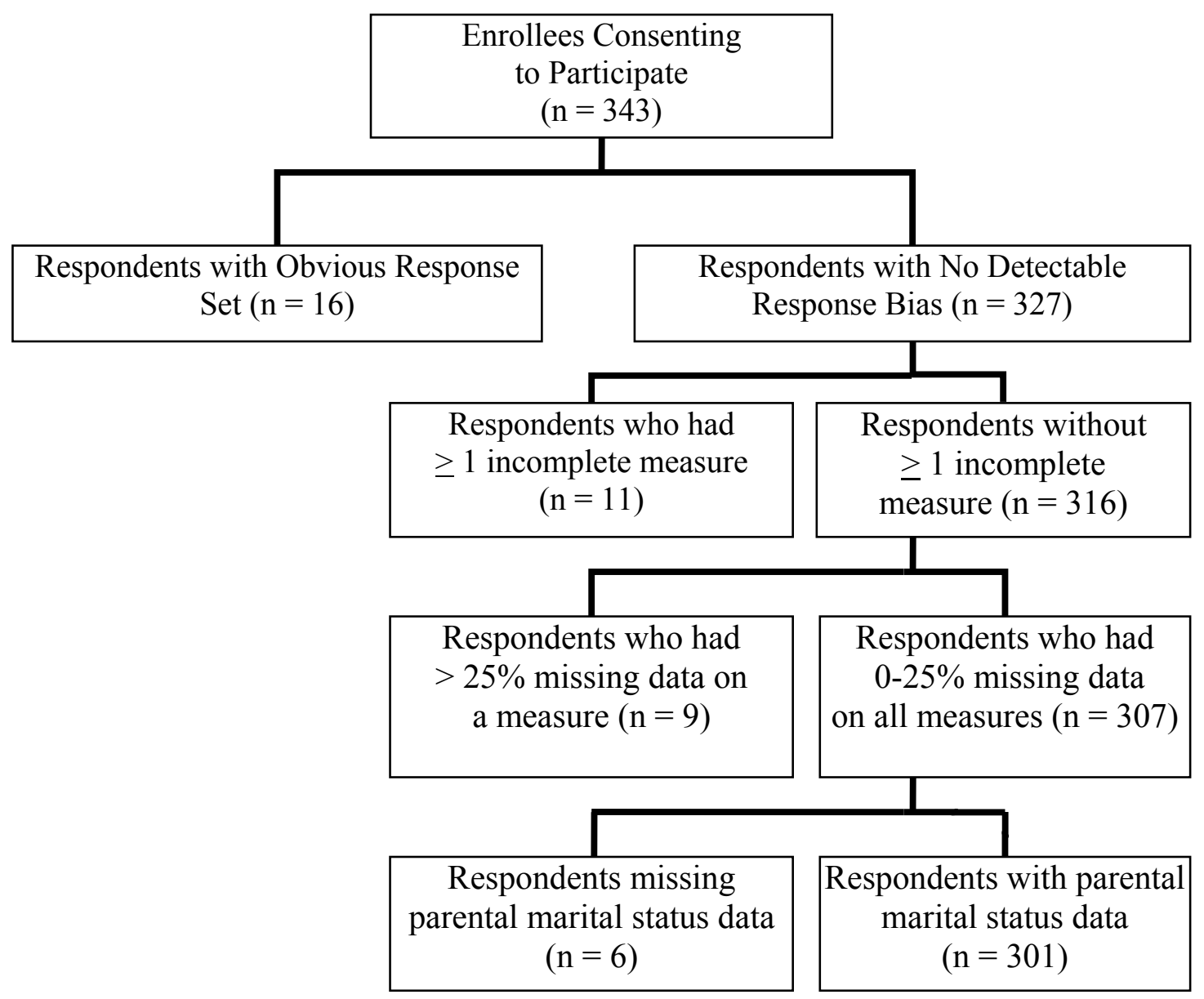

Figure 5. Flow chart showing reasons for data exclusion 
In reviewing their raw data, it was apparent that a few $(\mathrm{n}=16)$ individuals responded to one or more measures using an obvious response set (e.g., responded 'false' to all items on a scale with reverse scoring), an unfortunate artifact of anonymous survey completion. Because response sets cast suspicion on the verity of those participants' remaining data, data from these participants were excluded. Of the remaining 327 participants, eight subjects $(2.4 \%)$ failed to complete one entire measure, and three additional participants $(0.8 \%)$ left more than one entire measure incomplete during completion of the current study. Participants with at least one incomplete measure did not differ from those without incomplete measures on age, $t(323)=1.13$, $p>.05$, or on any categorical demographic variable (i.e., $\chi^{2}, \varphi$, or $\varphi_{\mathrm{c}}$ statistics), all $p \mathrm{~s}>.05$. There also were no significant differences between the two groups on any main predictor or outcome variables, $|t| \mathrm{s}<1.29$, all $p \mathrm{~s}>.05$. Given the absence of differences between those with and without entirely incomplete measures, data from the 11 participants who left at least one measure incomplete were excluded from further analyses.

Of the remaining 316 cases, nine cases contained at least one measure with more than $25 \%$ missing data. Those eight participants were not different from the other participants regarding age, $t(312)=-.68, p>.05$, or on any categorical demographic variable (i.e., $\chi^{2}, \varphi$, or $\varphi_{c}$ statistics), all $p \mathrm{~s}>.05$. Significant differences between those with and without more than $25 \%$ missing data on any measure also were not found on any path analytical variables, $|t| \mathrm{s}<1.77$, all $p \mathrm{~s}>.05$. Therefore, the nine participants missing more than $25 \%$ of any measure were not included in any following analyses as such an escalated level of imputation would be inappropriate.

From the 307 individuals with acceptably intact data, there were six individuals who either failed to respond to the items indicating parental divorce history or whose language was 
unclear in indicating whether divorces occurred in their families of origin. When comparing those with and without missing information on parental divorce, significant differences were observed between the groups on family forgiveness, $t(305)=2.87, p<.01$, threat associated with interparental conflict, $t(305)=-2.14, p<.05$, self-blame for interparental conflict, $t(305)=-3.45$, $p<.01$, support within the mother-child relationship, $t(305)=2.89, p<.01$, and negative interaction within both mother-child, $t(305)=-2.83, p<.01$, and father-child relationships, $t(305)=-2.57, p<.05$. When compared to those with available information on parental divorce $(M=13.30, S D=9.08)$, those missing pertinent information exhibited lower levels of family forgiveness $(M=1.60, S D=4.16)$. Higher perceived threat from interparental conflict was evident in the group with missing data $(M=2.12, S D=.43)$ compared to those providing parental divorce information $(M=1.67, S D=.46)$. Those missing parental marital status information also had higher self-blame for interparental conflict scores $(M=1.75, S D=.47)$ compared to those with intact information $(M=1.24, S D=.33)$. Participants missing information on parental divorce also showed lower social support within their maternal relationship $(M=$ $2.88, S D=.56)$ than those with intact data $(M=3.78, S D=.69)$. Further, mother-child relationship quality was more diminished by negative interactions for those with missing parental divorce data $(M=3.27, S D=1.12)$ relative to those who provided parental divorce history $(M=$ $2.18, S D=.85)$. Father-child relationship quality was also characterized more negatively among those missing parental divorce information $(M=2.97, S D=.92)$ compared to participants who provided such information $(M=1.96, S D=.87)$. The two groups did not differ on the remaining outcome variables, $|t| \mathrm{s}<1.67$, all $p \mathrm{~s}>.05$. Further, no differences were evident between the two groups on age $t(305)=-.11, p>.05$ or on any categorical demographic variable (i.e., $\chi^{2}, \varphi$, or $\varphi_{c}$ statistics), all $p \mathrm{~s}>.05$. As parental divorce was the main predictor of interest for the primary 
analyses, and is not logically subject to imputation, data for the six participants missing information on parental divorce were not included in any further analyses. Therefore, the final sample size for the current study was 301 participants.

Missing Data and Imputation Strategy. Although the remaining 301 participants responded at an acceptable level to each measure included in the primary study analyses, there were some who did not answer selected items on various measures. The distribution of participants regarding proportion of missing items is shown in Table 2. Percentage of missing data was not significantly correlated with any predictor or outcome variables, $|r| \mathrm{s}<.11$, all $p \mathrm{~s}>$ .05. Further analyses indicated that participants who had less than five percent missing data did not differ significantly from those who had more than five percent of their data missing on any path analytical variables, $|t| \mathrm{s}<1.09$, all $p \mathrm{~s}>.05$.

Imputation via the expectation maximization method in SPSS v16.0 was the final step in data preparation. Table 2 provides a summary of the percentage of data imputed for each overall measure. Data were imputed at the item level, scale scores were recalculated based on these item values, and recalculated scores were utilized in the primary analyses. Data were not imputed using AMOS v16.0, the software with which path analyses were conducted, because imputation using that program would have occurred at the scale level.

Assumptions for Path Analysis. Because path analysis assumes data are distributed normally, this assumption was tested by examining each variable used in the primary analysis for skewness, kurtosis, and presence of outliers. Skew and kurtosis were examined at the level of individual items and at the level of scale and subscale scores to be used in the path analytical models. The distributions of only one item from the CPICS showed skewness of 3.31 and kurtosis of 10.61. All other CPICS items' skewness and kurtosis were $<|3|$ and $<|10|$, 
respectively. No other items, subscales, or scales for any independent or outcome variable exhibited levels of skew or kurtosis (i.e., $<|3|$ and $<|10|$, respectively) that were outside acceptable limits (see Table 3).

Table 2. Numbers of participants with complete and incomplete data that for each variable used in the primary analyses.

\begin{tabular}{|l|l|l|l|l|}
\hline $\begin{array}{l}\text { Measure } \\
(\mathrm{n}=301)\end{array}$ & $\begin{array}{l}100 \% \text { complete } \\
(\text { i.e., } 0 \% \\
\text { imputed })\end{array}$ & $\begin{array}{l}95 \% \text { complete } \\
\text { (i.e., }<5 \% \\
\text { imputed })\end{array}$ & $\begin{array}{l}90 \% \text { complete } \\
\text { (i.e., }<10 \% \\
\text { imputed })\end{array}$ & $\begin{array}{l}75 \% \text { complete } \\
\text { (i.e., }<25 \% \\
\text { imputed })\end{array}$ \\
\hline NRI & 289 & 9 & 3 & 0 \\
\hline CPICS & 291 & 4 & 2 & 4 \\
\hline FFQ & 300 & 0 & 0 & 1 \\
\hline FPI & 293 & 5 & 2 & 2 \\
\hline BSQ & 292 & 6 & 1 & \\
\hline
\end{tabular}

To assess for outliers, Mahalanobis distance values and their associated $p$ values were calculated. Cases with $p$ values below the .001 level were considered to be significant multivariate outliers (see Table 3 for summary of outliers). When considering all variables within the path models simultaneously, six participants were multivariate outliers. When examining multivariate outliers based on conceptually related constructs, there were fewer outliers. Specifically, there were four cases that qualified as outliers on attachment scores (secure, dismissing, and preoccupied subscales of the BSQ). Three participants were outliers on all four indicators (maternal and paternal social support and negative interactions) of parent-child relationship quality. Only one participant's data qualified him or her as an outlier on both measures of forgiveness (i.e., family and participant). Two additional participants were outliers when considering the three indicators (conflict properties, self-blame, and threat) of 
Table 3. Skewness, kurtosis, and outliers for each study variable

\begin{tabular}{|c|c|c|c|c|}
\hline \multirow[t]{2}{*}{ Measure } & \multirow[t]{2}{*}{ Skew } & \multirow[t]{2}{*}{ Kurtosis } & \multicolumn{2}{|c|}{ Outliers } \\
\hline & & & $\begin{array}{l}\text { Scale } \\
\text { level }\end{array}$ & $\begin{array}{l}\text { Overall } \\
\text { level }\end{array}$ \\
\hline \multicolumn{4}{|c|}{ Parent-child Relationship Quality (NRI) } & \multirow{16}{*}{6} \\
\hline - Maternal Social Support & -.63 & .09 & \multirow{4}{*}{3} & \\
\hline - Maternal Neg. Interaction & .82 & .42 & & \\
\hline - $\quad$ Paternal Social Support & -.82 & .51 & & \\
\hline - Paternal Neg. Interaction & 1.21 & 1.49 & & \\
\hline \multicolumn{4}{|l|}{ Interparental Conflict (CPICS) } & \\
\hline - Conflict Properties & .58 & -.54 & \multirow{3}{*}{2} & \\
\hline - Threat & .90 & .13 & & \\
\hline - $\quad$ Self-Blame & 1.43 & 1.23 & & \\
\hline \multicolumn{4}{|l|}{ Forgiveness } & \\
\hline • FFQ & -.67 & -.30 & \multirow{2}{*}{1} & \\
\hline$\bullet \quad$ FPI & -.17 & .03 & & \\
\hline \multicolumn{4}{|l|}{ Attachment (BSQ) } & \\
\hline - Secure Attachment & -.93 & 1.37 & \multirow{3}{*}{4} & \\
\hline - Dismissing Attachment & .56 & .21 & & \\
\hline - $\quad$ Preoccupied Attachment & .41 & -.10 & & \\
\hline
\end{tabular}

interparental conflict together. No transformation of data or deletion of cases occurred due to these outliers for three reasons. First, their scores were inspected and values on the relevant measures did not appear erroneous but were somewhat extreme. Their responses were, therefore, considered meaningful portions of the data set. Second, because only one item on any of the current study's measures exhibited skew and kurtosis that were above ideal limits (see above), it was not considered necessary to transform the outliers to increase normality within the data. Last and related to the prior reason, there were very few outliers when considering overall sample size.

Demographic Variables.

Prior to conducting the path analyses to test study hypotheses, relations between study variables and demographic participant characteristics were examined. Three sets of analyses 
were conducted, the first examining sex of study participants, the second assessing the ethnicity of participants, and the third examining variables linked with socio-economic status. Data from all 301 participants were utilized in these data analyses. Due to the number of analyses, the threshold for significance of results was lowered to $p<.01$.

Sex. To determine whether study variables differed depending upon the participant sex, a series of analyses of variance (ANOVAs) was conducted. Table 4 contains results of the ANOVAs. Significant differences were found between men and women in maternal social support, participant forgiveness, secure attachment, and dismissing attachment. Women reported more maternal social support, participant forgiveness, secure attachment, and less dismissing attachment than men. Because men and women differed on two of three attachment outcomes, sex was used as a covariate in all models. Two participants failed to indicate sex, which thereby precluded their data from being used in analyses. Therefore, the final sample size was reduced from 301 to 299 .

Ethnicity. ANOVAs were conducted for ethnicity as well to ascertain whether study variables differed between Whites and non-Whites. There were no significant differences between Whites and non-Whites on any variables of interest. Table 5 lists means, standard deviations, and $F$ s for these analyses.

Socio-Economic Status. Although a comprehensive measurement of socio-economic status was not obtained in this study, several items reflecting elements of socio-economic status were assessed (i.e., maternal and paternal educational achievement; difficulty paying bills in household while growing up). As these items reflected ordinal rather than interval data, Spearman rho correlation coefficients were calculated instead of Pearson correlation coefficients. Results of these analyses are shown in Table 6. Although no significant relations were observed 
between maternal education and study variables, paternal education was positively associated with the measure of paternal social support. The final variable linked with socioeconomic status, difficulty paying bills, was associated with more negative maternal interactions, poorer social support in the paternal relationship, increased conflict among parents, and increased threat felt due to interparental conflict.

\section{Univariate Associations among Predictor and Outcome Variables. Seventy-seven} participants $(25.8 \%)$ reported experiencing parental divorce in their household and 222 participants (74.2\%) reported having intact families while growing up. Univariate correlation coefficients were calculated to examine the inter-correlations among all study variables (see Table 7). Correlation coefficients among all variables are Pearson correlation coefficients, except for those with parental divorce status; because parental divorce status was a categorical variable, point biserial correlation coefficients were used for examining associations with this variable. A .01 confidence level was used to evaluate the statistical significance of these correlations due to the number of correlational analyses conducted.

Univariate associations were observed between parental divorce status and several outcome variables measured in this study. The experience of parental divorce was associated with less paternal social support, greater threat due to interparental conflict, higher interparental conflict properties scores, and lower levels of family forgiveness.

Significant associations also existed between measures of attachment and other variables of interest. Secure attachment was related to more maternal social support, family forgiveness, and participant forgiveness. Dismissing attachment was associated positively with self-blame for interparental conflict. Elevated scores on dismissing attachment were also related to lower maternal social support, family forgiveness, and individual forgiveness. Finally, preoccupied 
attachment was related to less maternal social support, family forgiveness, and participant forgiveness, but more maternal negative interaction and higher scores on all three subscales of interparental conflict.

The two forgiveness variables were also associated with aspects of parental relationship quality. Maternal and paternal social support were positively related to both individual and family forgiveness. Negative interactions with mothers and fathers were significantly negatively correlated with family forgiveness, and paternal negative interactions were also significantly and negatively associated with participant forgiveness. Univariate relations between forgiveness and interparental conflict subscales were also significant. Specifically, both family and participant forgiveness were significantly and inversely associated with all three CPICS subscales. Therefore, higher individual and family forgiveness was associated with lower scores on interparental conflict measures.

Finally, there were several significant correlations between measures of parental relationships and interparental conflict. Maternal negative interaction was significantly correlated with all three interparental conflict (CPICS) subscales, and paternal negative interaction was significantly correlated with conflict and perceived threat associated with parental conflict. In contrast, maternal social support was inversely associated with self blame, and paternal social support was inversely associated with conflict and perceived threat associated with parental conflict.

\section{Path Analyses Examining Primary Study Hypotheses}

Due to significant differences between sexes on two of three attachment outcomes (i.e., secure and dismissing), sex was included as a covariate in all path models. For all models, covariances that were not significant were trimmed from the models and are not depicted in the 
path diagrams. Also, modification indices consistently indicated improvement in model fit with covariance of disturbances for Secure and Dismissing Attachment. Therefore, that covariance was included in all path models. Path analyses were performed with AMOS v16.0, and follow-up regression analyses were performed using SPSS v16.0.

Preliminary Path Models

Parent-child Relationship Quality. Fig. 6 depicts the hypothesized path model for parentchild relationship quality. The model exhibited satisfactory model-data fit indices without any modifications, $\chi^{2}=24.612, \mathrm{df}=24, p>.05 ; \mathrm{CFI}=.999, \mathrm{RMSEA}=.009$.

Standardized and unstandardized path coefficients for the model are presented in Table 8 . Partial support was found for hypothesized moderation of the relation between parental divorce and attachment by parent-child relationship quality. For purposes of presenting results succinctly, only significant moderation (i.e., interaction) effects will be discussed.

The relations between parental divorce and attachment were significantly moderated by both maternal and paternal social support. The paths between the Parental Divorce X Maternal Social Support interaction term and Secure and Preoccupied (but not Dismissing) Attachment were significant. Follow-up regressions showed that Maternal Social Support was positively associated with Secure Attachment for individuals from intact families $\left(R^{2}=.04, \beta=.20, p<\right.$ .01), whereas Maternal Social Support was not significantly related to Secure Attachment for those whose parents were divorced $(\beta=.08, p>.05)$. Additional follow-up regressions indicated that Maternal Social Support shared a significant negative relation with Preoccupied attachment for individuals with divorced parents $\left(R^{2}=.09, \beta=-.29, p=.01\right)$, whereas Maternal Social Support was not significantly related to Preoccupied Attachment for individuals with intact parents $(\beta=-.05, p>.05)$. In addition to Maternal Social Support's moderation of parental 


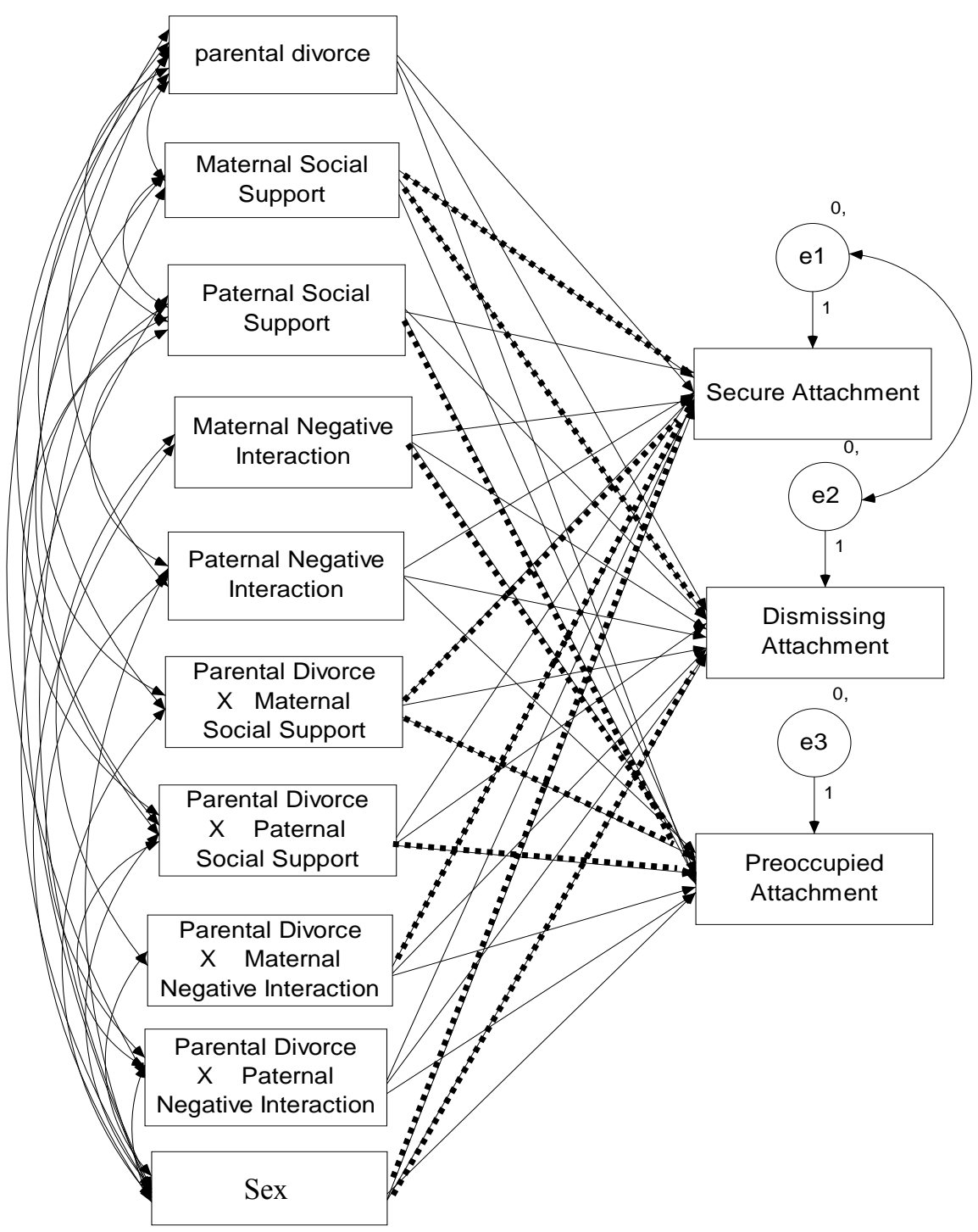

Figure 6. Parent-child relationship quality path model. Paths reinforced with hyphenated lines were significant.

divorce's effects on Preoccupied Attachment, Paternal Social Support also moderated the relation between parental divorce and Preoccupied Attachment. For participants who reported that their parents' marriage was intact, Paternal Social Support was negatively related to Preoccupied Attachment $\left(R^{2}=.04, \beta=-.20, p<.01\right)$. Paternal Social Support was not significantly related to Preoccupied Attachment for participants reporting parental divorce $(\beta=$ $.12, p>.05)$ 
Evidence for another moderation of the relation between parental divorce and attachment was apparent as well. Maternal Negative Interaction moderated the relation between parental divorce and Secure (but not Dismissing or Preoccupied) Attachment. Specifically, regression results indicated a negative relation between Maternal Negative Interaction and Secure Attachment for individuals with history of parental divorce $\left(R^{2}=.07, \beta=-.25, p<.05\right)$. Maternal Negative Interaction was not significantly related to Secure Attachment for participants with intact parents, however $(\beta=-.03, p>.05)$.

Interparental Conflict. The data did not fit the hypothesized path for the initial interparental conflict path analysis, $\chi^{2}=27.28, \mathrm{df}=8, p=.001 ; \mathrm{CFI}=.981, \mathrm{RMSEA}=.090$. The data-model fit indices were improved, however, after changes were made based on critical ratios, $\chi^{2}=36.612, \mathrm{df}=19, p<.01 ; \mathrm{CFI}=.983, \mathrm{RMSEA}=.056($ Fig. 7$)$.

Standardized and unstandardized path coefficients for the interparental conflict path model are shown in Table 9. The hypothesis that interparental conflict would moderate the relation between parental divorce in attachment was not supported, although significant paths were apparent between individual facets of interparental conflict and attachment dimensions.

Family and Individual/Participant Forgiveness. Similar to the hypothesized path model for interparental conflict, the initial forgiveness path model exhibited poor model fit, $\chi^{2}=19.23$, $\mathrm{df}=4, p=.001 ; \mathrm{CFI}=.964, \mathrm{RMSEA}=.113$. Data-model fit improved following constraint of the paths between parental divorce and all attachment dimensions to zero, which was based on extremely low, non-significant critical ratios associated with those paths, $\chi^{2}=21.20, \mathrm{df}=7, p<$ $.01 ; \mathrm{CFI}=.966, \mathrm{RMSEA}=.082$. The addition of a covariance term between sex and participant forgiveness' disturbance term, which based on a modification index provided upon initial path 


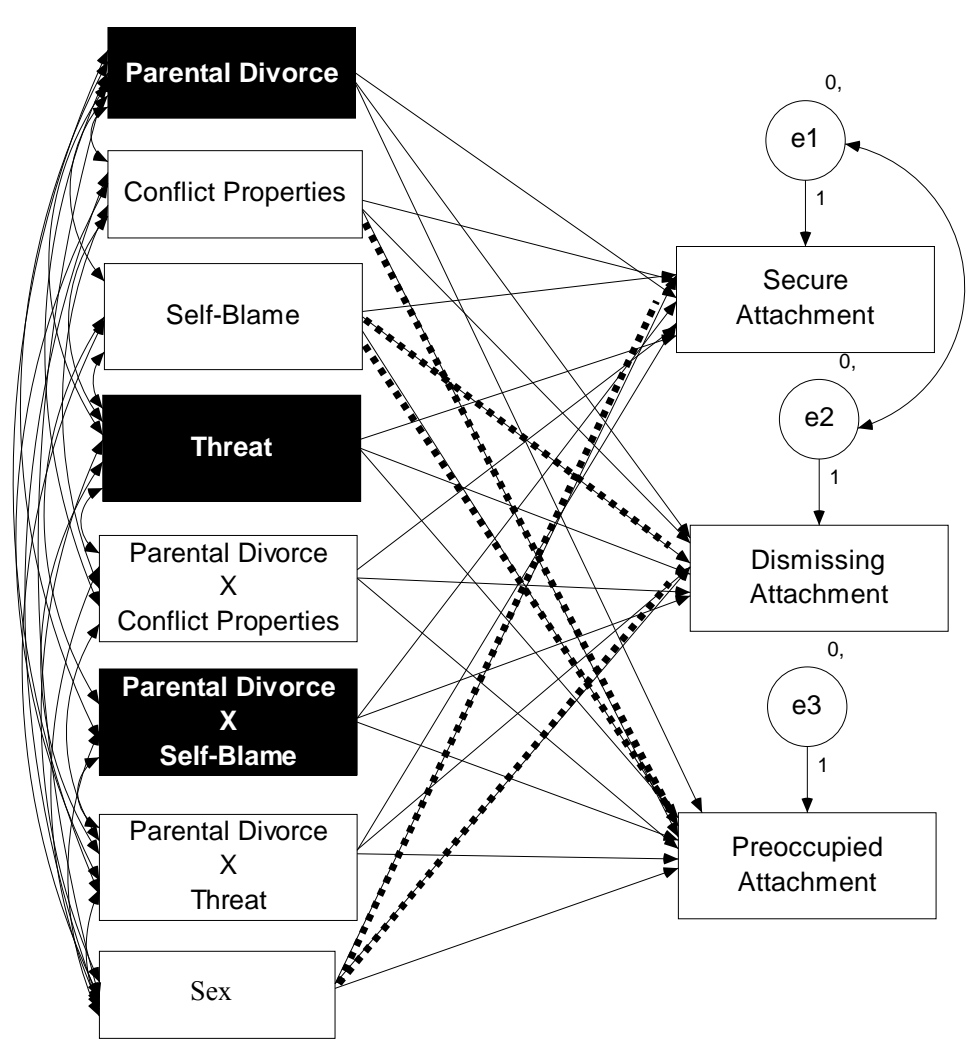

Figure 7. Modified interparental conflict path model. Some paths associated with highlighted

analysis of the forgiveness model, improved the data-model fit further, $\chi^{2}=6.23, \mathrm{df}=6, p>.05$; $\mathrm{CFI}=.999, \mathrm{RMSEA}=.011($ Fig. 8).

Table 10 contains both standardized and unstandardized path coefficients for the final forgiveness model. Hypothesized moderation of the association between Parental Divorce and Attachment by Family Forgiveness was partially supported in that Family Forgiveness moderated the relation between parental divorce and Dismissing (but not Secure or Preoccupied) Attachment. According to follow-up regressions, a significant negative association was evident between Family Forgiveness and Dismissing attachment in the subset of the sample who had not experienced parental divorce $\left(R^{2}=.09, \beta=-.30, p<.001\right)$. Such significant results were not apparent for participants who reported parental divorce $(\beta=-.20, p>.05)$. Additionally, Family 


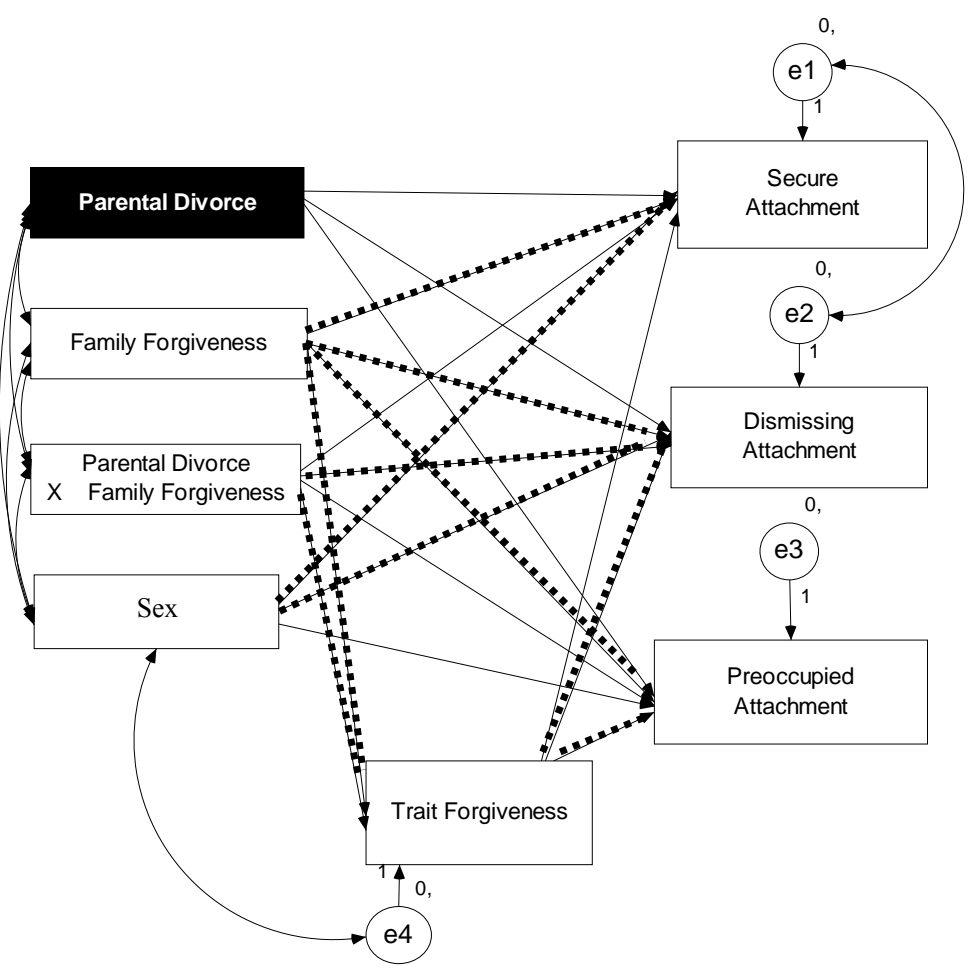

Figure 8. Modified path model for forgiveness. All paths associated with the highlighted variables were constrained to 0 . Paths reinforced with hyphenated lines were significant.

Forgiveness and Participant Forgiveness were significantly and positively related $\left(R^{2}=.36, \beta=\right.$ $.60, p<.001)$, and this relation was moderated by Parental Divorce. Although the relation was significant among both participants of divorced and intact households, the effect was larger for individuals reporting parental divorce compared to individuals with intact parents $\left(R^{2}=.09, \beta=\right.$ $.29, p<.001)$.

\section{Overall Path Models}

Based on significant findings from the preliminary path models, an overall model was built. Paths exhibiting critical ratios $\geq 1.96$ (i.e., $p<.05$ ) were incorporated as predictors into an overall model with Attachment scores (Secure, Dismissing, and Preoccupied) as the outcomes of interest. The initial model assembled is depicted in Figure 9. 
The model exhibited sufficient data-model fit, $\chi^{2}=62.49, \mathrm{df}=53, p>.05 ; \mathrm{CFI}=.991$, RMSEA $=.025$. Some paths that were significant in the preliminary models were no longer significant in the context of the comprehensive model. However, all significant paths between interaction terms and attachment outcomes observed in the preliminary path analyses remained significant. In other words, facets of parent-child relationship quality and family forgiveness that moderated the relation between parental divorce and attachment in the preliminary models continued to do so in the overall path model. Standardized and unstandardized path coefficients for all paths are contained in Table 11.

\section{Mediation Analyses}

Based on the overall path model, mediation analyses were conducted for Participant Forgiveness mediating the relation between Family Forgiveness, as well as its interaction with Parental Divorce, and dimensions of attachment that shared significant paths with those forgiveness variables. First, potential mediation of relations between Family Forgiveness and both Dismissing and Preoccupied (but not Secure) Attachment was examined by conducting Sobel tests with model path coefficients and their respective standard errors as input. Sobel tests indicated that Participant Forgiveness significantly mediated the relation between Family Forgiveness and Dismissing Attachment $(z=-.312, p<.01)$, illustrating that participants' families' levels of forgiveness negatively influenced Dismissing Attachment indirectly via its influence on Participant Forgiveness. Mediation by Participant Forgiveness of the relation between Dismissing Attachment and the interaction between Parental Divorce and Family Forgiveness also was analyzed. A Sobel test of mediation indicated a significant mediation effect $(z=2.21, p<.05)$. In other words, Family Forgiveness exerted influence on Dismissing Attachment for individuals with intact parents indirectly through its relation to Participant 


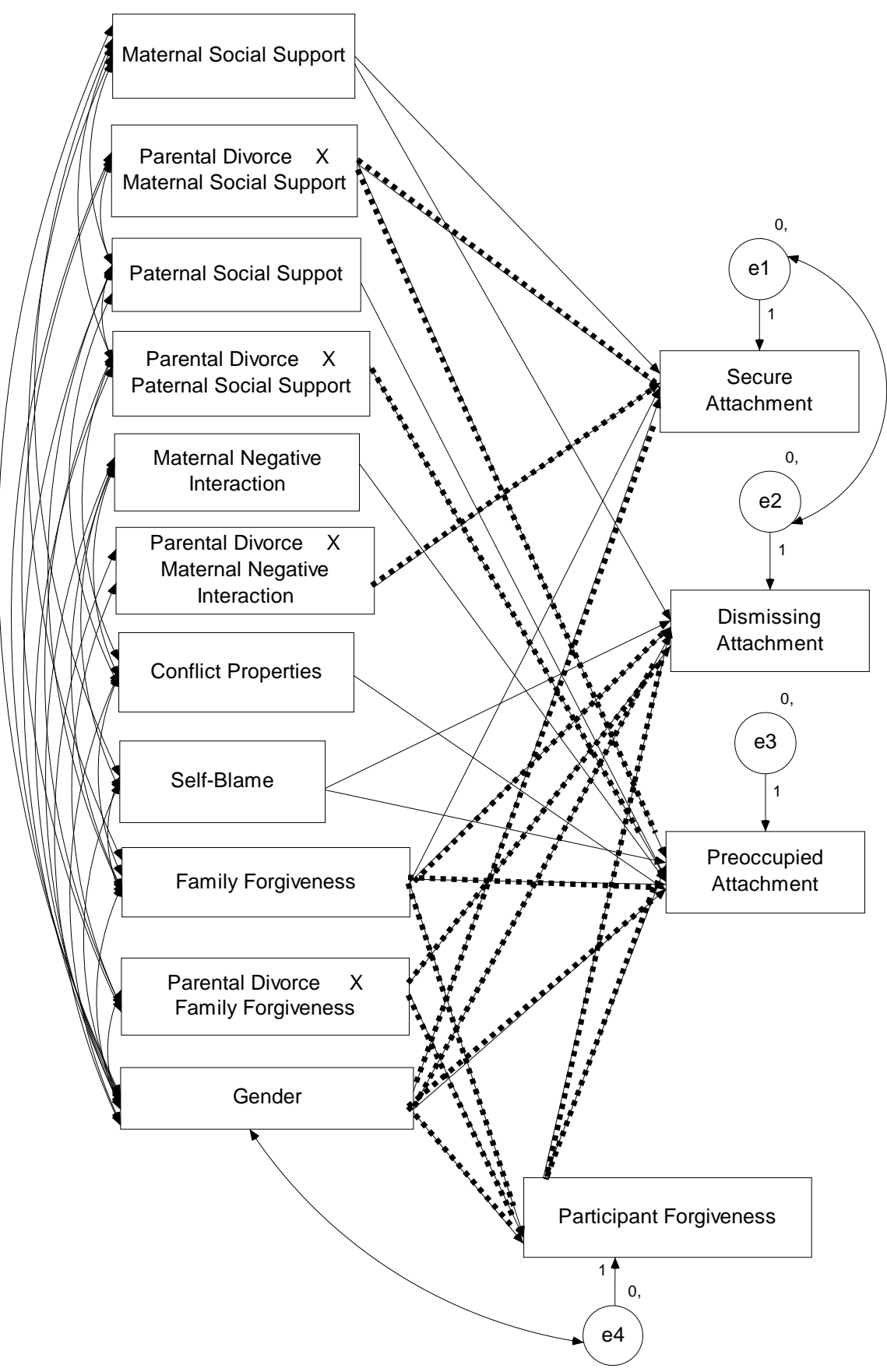

Figure 9. Overall path model. Paths reinforced with hyphenated lines were significant.

Forgiveness. Taken together, those results clearly indicate that (1) Family Forgiveness is associated with Participant Forgiveness, (2) Participant Forgiveness, in turn, is negatively associated with levels of Dismissing Attachment, (3) and that such relations appear to be particularly applicable to participants whose parents' marriages are intact. 
Participant Forgiveness did not significantly mediate the association between Family Forgiveness and Preoccupied Attachment $(z=-1.90, p>.05)$. However, it should be noted that the mediation of the relation between Family Forgiveness and Preoccupied Attachment fell only slightly short of the $z$-statistic criterion (i.e., 1.96) and would be considered significant if the criterion for statistical significance was less conservative (i.e., $p<.10$ ). For purposes of the current investigation, however, the finding will not be considered significant. Further, despite lack of meditation effects by Participant Forgiveness and effects of moderation by parental divorce, Family Forgiveness nonetheless was significantly and inversely related to Preoccupied Attachment (see Table 10).

\section{Discussion}

The influence of parental divorce on the development of satisfactory relationship building and maintaining skills as individuals emerge into adulthood is not well understood. To better understand factors that influence this relation, the current study explored the role of parent-child relationship quality, presence of interparental conflict, and family styles of forgiveness as potential moderators. Overall, results provided support for several hypothesized moderators of the association between parental marital status and adult romantic attachment; however, not all variables included in this study were found to moderate this relation. Presence or absence of parental divorce history, the predictor variable common to all hypothesized path models and all interactions that served as proxies to test moderation, itself was not significantly related to attachment outcomes. Such a finding aligns with prior research failing to find support for the link between parental divorce and romantic attachment (Brennan \& Shaver, 1993; Hazan \& Shaver, 1987; Hazelton et al., 1998; Lawler-Row et al, 2006; Lopez et al., 2000). However, as noted earlier, several investigations have shown significant associations between parental divorce and 
subsequent measures of attachment quality (Brennan \& Shaver, 1998; Killman et al., 2006;

Lewis et al., 2000; Summers et al., 1998; Waters et al., 2000), which prompted the current exploration of other factors that might influence the association.

It was considered imperative to determine which aspects of parent-child relationship quality, interparental conflict, and forgiveness worked together to affect quality of attachment within romantic relationships via the current investigation. This was the case primarily because separate explorations of factors affecting romantic attachment had already been reported in the literature, but no one had yet comprehensively examined how they may fare in their relation to attachment within the context of each other. To determine first which independent variables were observed to relate to attachment and/or moderate the relation between it and parental divorce, variables were examined in individual path models. Comprehensive path models then were constructed based on significant contributors within the preliminary individual path models. The following variables were entered into the overall path model, with the three attachment dimensions included as outcomes: Maternal Social Support, Paternal Social Support, Maternal Negative Interaction, interparental Conflict Properties, Self-blame for interparental conflict, Family Forgiveness, Participant Forgiveness, Parental Divorce X Maternal Social Support, Parental Divorce X Paternal Social Support, Parental Divorce X Maternal Negative Interaction, Parental Divorce X Family Forgiveness. Though all variables, when considered in individual path models, were significantly related to at least one of the attachment measures, some were no longer significant in the context of the larger model. Discussion of the results for the overall path model follows, organized by conceptually related predictors (e.g., Parent-Child Relationship Quality variables). 


\section{Parent-Child Relationship Quality and Attachment}

Several aspects of the parent-child relationship, such as level of parental care or overprotection, have been found to predict avoidance and anxiety of adult attachment for White men and women from both intact and divorced families (Lopez et al., 2000). In the current study, parental divorce interacted significantly with maternal social support, maternal negative interaction, and paternal social support in their relations to secure and/or preoccupied romantic attachment. Solely for participants with intact parents, high levels of maternal social support were associated with more secure attachment. This finding suggests that reported positive interactions between participants and their mothers during childhood may have provided the foundation for confidence in, and comfort with, romantic partners for participants in emerging adulthood. Roisman, Madsen, Hennighausen, Sroufe, and Collins (2001) assessed the relation between parent-child behaviors during observed interactions in adolescence and interactions between the participants and their romantic partners in early adulthood. Two variables of interest were parent-child process and romantic relationship process, which were each comprised of several factors. Parent-child process involved acceptance of, expression of, and responding to each others' feelings and ideas. Parent-child process also included emotional engagement and positive affect, among other variables. Romantic relationship process encompassed accepting, expressing, and responding to feelings and ideas by the partners as well, in addition to other factors such as evidence of a secure base and shared positive affect. In this study, parent-child process during adolescence was significantly and positively related to later romantic relationship process. Their results supported the idea that support and positivity in the parent-child relationship was associated with support, positivity, and security in later romantic partnerships, 
which aligns with the current study's finding that maternal social support was positively related to secure attachment.

Roisman et al. (2001) examined primary caregivers' interactions with their children, so it is possible that the sample included fathers in addition to mothers. However, mothers more often fulfill the role of primary caregiver. Therefore, the effects that were evident in their study may be largely attributable to support from mothers. They also may account for lack of a significant relation between paternal social support and secure attachment in this investigation. However, a significant inverse relation was evident among paternal social support and preoccupied attachment for participants whose parents' marriages were intact. Physical paternal presence was consistent for these participants, which allowed the potential for more consistent paternal social support throughout childhood and adolescence compared to individuals who experienced separation of their parents. In the context of adequate social support from their fathers, participants whose parents remained married may not have developed concerns about instability or abandonment in their romantic relationships because such features were not salient in their parents' marriage due to its intact nature. Paternal social support may not buffer sufficiently against those concerns for persons who experienced parental divorce, which could instigate worries of instability in participants' own romantic relationships. In sum, current attachment in romantic relationships among participants from intact families benefited from both maternal and paternal social support received from their parents.

Among participants with divorced parents, maternal social support was associated significantly with less preoccupied attachment, a finding not observed among those whose parents' marriages remained intact. Again, the work of Roisman and colleagues (2001) is relevant. Romantic relationship process, a component of which was observation of secure base in 
interactions between participants and their romantic partners, was positively associated with a conglomerate measure of parent-child process that included elements of parental support. As that aligns with the current finding of a positive relation between maternal social support and secure attachment that was previously detailed, it is understandable to extend that logic to align with the negative association observed in the current study between maternal social support and preoccupied attachment. Whereas the relation between maternal social support and secure attachment was significant only for participants whose parents were married, the inverse association between maternal social support and preoccupied attachment was significant only for participants whose parents had divorced. It is reasonable to suspect that, because children more often stay with their mothers following divorce, receiving support from one's maternal figure is particularly important for later romantic attachment amidst a climate of parental marital failure. Maternal support provided during such a time could serve as a model for a less preoccupied attachment style for those children in later romantic relationships — despite the fact that experiencing parental divorce may otherwise foster proclivity toward more preoccupied attachment through learning that romantic relationships are unstable and prone to failure.

The results of Roisman et al. (2001) also are congruent with the negative association observed between maternal negative interaction and secure attachment discovered in the current study's sample. Specifically, reports of more maternal negative interaction were associated with reports of less secure attachment in the subset of participants who reported having experienced parental divorce. As sufficient maternal social support for individuals with divorced parents may have buffered the potential for heightened preoccupied attachment, heightened levels of negative maternal negative interactions reported by those with divorced parents appears to have a link to lowered security of romantic attachment. Because mothers often serve as primary caregivers, the 
current results indicate that quality of that mother-child relationship may be particularly important for developing healthy romantic attachments in emerging adulthood. That importance is especially relevant for individuals with divorced parents, whose attachment was more secure and less preoccupied on average when negative interactions with their mothers were low and support from their mothers was high.

\section{Interparental Conflict and Attachment}

As no aspects of interparental conflict interacted with parental divorce to significantly relate to any attachment dimension in the current sample according to preliminary path analyses, no such interaction terms were entered into the overall path model. Although they did not interact with parental divorce, interparental conflict properties and self-blame for interparental conflict were significantly related to attachment. However, when considered alongside other variables of interest in the overall path model, neither of those factors emerged as significant associates of secure, dismissing, or preoccupied attachment. This is in contrast to findings of previous investigations showing that attachment was more insecure when interparental conflict was higher (Davies et al., 2002; Kenny \& Donaldson, 1991). Though not found currently, an association between interparental conflict properties and attachment was expected because frequency and intensity of interparental conflict is reflected in that measure. Additionally, Davies and his colleagues (2002) discovered that emotional responses were more negative during an analog parental conflict situation when the conflict content was related to the child or to family dissolution. Therefore, a significant relation between self-blame for interparental conflict and reduced security in romantic attachment might be extrapolated. However, such evidence was not present in this investigation. Discrepancies in findings relating interparental conflict and attachment may be attributable to the type of attachment examined. Kenny and Donaldson 
(1991) as well as Davies et al. (2002) examined security reflected within the parent-child domain, whereas the current investigation focused on romantic attachment during emerging adulthood. Therefore, findings from those previous studies may not generalize to the investigation of romantic attachment, at least when interparental conflict is considered within the context of other independent variables that may exert stronger effects and thereby overshadow the effects of interparental conflict that were present when considered in isolation.

\section{Forgiveness and Attachment}

As outlined in the introduction, parent forgiveness has been shown to relate to offspring forgiveness (Hoyt, Fincham, McCullough, Maio, \& Davila, 2005; Maio, Fincham, Thomas, \& Carnelley, 2008; Mullet et al., 2004; Mullet et al., 2006; Neal, 2006; Subkoviak et al., 1995). In keeping with the concept of the potential intergenerational transfer of forgiveness, Family Forgiveness was explored in the current investigation. In conjunction with the assessment of participant forgiveness, such exploration was an attempt to capture how learning about conflict resolution in the family may be transmitted to a personal approach toward forgiveness in romantic relationships in emerging adulthood. Several studies have shown there to be a significant link between an individual's own level of forgiveness and attachment, whereby more forgiving persons typically report more secure attachment, romantic and otherwise (BlountMatthews, 2005; Burnette et al., 2007; Crawley, 2006; Davidson, 2001; Hanford, 2006; LawlerRow et al., 2006; Luebbert, 2000; Mikulincer \& Goodman, 2006; Webb et al., 2006).

Evidence that partially replicated prior research was apparent for the association among parental divorce, family forgiveness, participant forgiveness, and attachment. First, how one's family forgave was associated with reports of dismissing romantic attachment, whereby higher family forgiveness was connected to less dismissing attachment. Further, family forgiveness 
moderated the association between parental divorce and dismissing attachment. For participants who reported that their parents' marriages were intact, higher levels of family forgiveness were related to less dismissing attachment. Finally, that significant effect was mediated by participants' own reports of forgiveness; for participants who reported never experiencing parental divorce, reports of higher family forgiveness were related to less dismissing attachment indirectly through their effect on individual forgiveness. In other words, it may be plausible that the extent to which one's family forgave transgressions while growing up influenced one's individual style of forgiveness, which in turn affected how dismissing one's attachment was to romantic partners. In such a way, histories of increased personal and family forgiveness may predispose individuals to be less distant and dismissive in their romantic relationships, possibly through the decreased likelihood of avoiding or poorly resolving conflict due to lack of a sufficient skill set in the area. Assessing such specific conjectures would require longitudinal research incorporating behavioral assessments of interactions within romantic attachment relationships, particularly those pertaining to conflict and its management. Because relations were restricted to participants who did not report parental divorce, it appears that a continuous, cohesive family setting in which to witness, experience, and learn forgiveness skills is a key component of establishing healthier personal forgiveness and romantic attachments in emerging adulthood.

Further, reports of higher family forgiveness were associated with reports of lower preoccupied attachment. Evidence for moderation of that relation by parental divorce was absent, which indicates that the relation did not differ significantly for participants whose parents remained married in comparison to those who reported experiencing parental divorce. Participant forgiveness was also associated positively with family forgiveness and negatively with 
preoccupied attachment, although individual forgiveness did not serve as a mediator of the relation between family forgiveness and preoccupied attachment. Again, the findings seem to indicate that one's own level of forgiveness, one's involvement in forgiveness in the broader context of the family while growing up, and the extent to which one exhibits anxiety, worry, preoccupation, etc. in romantic relations are linked to each other.

No research to date has examined family forgiveness and its relation to romantic attachment. Therefore, current results encourage investigation of such a relation in the future to replicate or further explore the nature of the association. Further, the fact that reports of how one's family forgave as they grew up are related to (either directly or through moderated or mediated pathways) reports of dismissing and preoccupied — but not secure — attachment highlights the necessity to avoid reducing participant scores to reflect only secure and insecure dimensions. Unfortunately, the practice of such reduction is more common than obtaining separate scores for specific attachment dimensions. Preoccupied and dismissing attachment behaviors are distinct from each other, and they also are distinct from secure attachment behaviors. Specifically, assessing outcomes relevant to forgiveness or to any other factor of interest will allow more informative conclusions and applications of findings.

\section{Summary and Conclusions}

In considering all the prior evidence across domains conjunctively, it appears plausible that the literature is divided in finding a direct link between parental marital status and adult romantic attachment at least partially because additional factors are exerting influence. Parental divorce was not related independently to secure, dismissing, or preoccupied attachment levels. Instead, moderating factors were associated with different attachment dimensions differently for those from divorced and intact family households. Specifically, maternal and paternal social 
support, maternal negative interactions, and family forgiveness were significant moderators of parental divorce-attachment relations. Participant forgiveness also served as a mediator of the relation between family forgiveness and dismissing attachment that was only applicable for individuals whose parents were in intact marriages. It is therefore clear that considerations beyond parental marital status alone need to be considered in understanding the potential etiology of attachment functioning in romantic relationships during young adulthood. However, due to evidence of moderation effects, parental marital status remains a factor of interest in the exploration of romantic attachment.

Results also are encouraging in that forgiveness, which was negatively related to the undesirable dimensions of attachment (i.e., dismissing and preoccupied), is potentially vulnerable to intervention. In contrast, the negative factors related to parental and family history (e.g., negative parental interactions; presence of parental support) that influence current attachment patterns in young adults are not susceptible to intervention. If one can cultivate forgiveness behaviors early in adulthood, decreases in dismissiveness and preoccupation within romantic relationships might occur. Intervention studies are therefore merited to address that possibility, especially to discern whether such changes might override the negative influences of diminished parent-child relationship quality (i.e., maternal and paternal social support, maternal negative interaction) on attachment outcomes.

Several limitations should be considered regarding the current study. The sample was restricted in a few ways, which limits generalizability of findings. First, the sample was restricted to a college-aged sample, so the findings regarding factors affecting adult attachment cannot be extrapolated beyond the low- to mid-20s age range or to those within this age range but who are not attending college. It is possible that romantic attachment is influenced by family history 
variables due to their temporally proximate influence on romantic attachment behaviors during emerging adulthood that may fade over time. Second, there were fewer than 100 male participants, which may have affected the power of some analyses, particularly path analytical analyses. Because sex of participant was significantly related to secure and dismissing attachment dimensions, it was used as a covariate in all path models. However, with sufficient and equal samples of men and women, the preferable route of assessing sex differences in findings could be executed. Third, as is the case with many samples drawn from pools of university students, the current sample was not ethnically or socioeconomically diverse (i.e., few non-White, low SES participants). Therefore, it is not valid to presume that findings in the current study would extend to members of other ethnic or socioeconomic backgrounds. Future studies should target such populations to further illustrate under which circumstances interparental conflict and forgiveness may relate to romantic attachment. For example, lower family income may create more household conflict over finances, which may in turn affect individual forgiveness and attachment within romantic relationships differently for children who witness adequate versus poor family forgiveness in such an environment during childhood and adolescence.

Another caveat of which to be mindful in interpreting the results of this study is that measurement occurred concurrently for observed/predictor and outcome variables. Due to simultaneous measurement of these constructs, causal relations between independent and dependent variables of interests cannot be ascertained. Although assessment of family history variables targeted past childhood experiences and romantic attachment assessment related to current experiences, reports for each occurred at the same time. On a related note, because a longitudinal design was not implemented, retrospective reports were necessary, and current 
romantic attachment and other experiences may color reports of prior experiences about which participants reported. However, significant findings from the current study indicate that causal links are plausible and are worth future longitudinal investigations mentioned above.

An additional consideration for future investigations of the factors explored in this study is specific to utilization of structural equation modeling techniques for statistical analyses. As is evident in the path models depicted earlier, separate subscales were included as separate independent variables in preliminary and overall path models. Creating latent variables (e.g., parent-relationship quality) with the subscales (e.g., maternal and paternal social support, maternal and paternal negative interaction) may be advisable to promote more succinct, better fitting models.

As expected, relations between parental divorce and dimensions of romantic attachment in emerging adulthood were not evident in their simplest, most direct form. Rather, the associations were moderated by aspects of parent-child relationship quality and family forgiveness, whereas aspects of interparental conflict failed to have significant direct effects on romantic attachment or to moderate the association between parental divorce and romantic attachment. Overall, results suggest that growing up in an environment with ample social support from parents and minimal negative interactions with mothers may be particularly important in the development of healthy romantic attachments during emerging adulthood. Family forgiveness, a construct not investigated in the romantic attachment literature thus far, also emerged as a factor of significant interest as it was associated with romantic attachment outcomes, often indirectly through its effects on personal forgiveness. Further, those associations differed at times depending on the status of the marriage of one's parents. Therefore, parental marital status remains important, but its effects are more complicated than a direct association 
with romantic attachment. Given the current findings, future investigators face the tasks of necessarily testing such processes longitudinally to determine causality and incorporating the influence of family and personal forgiveness on romantic attachment development. 


\section{References}

Ainsworth, M.D.S., Blehar, M.C., Waters, E., \& Wall, S. (1978). Patterns of attachment: A psychological study of the strange situation. Hillsdale: Lawrence Erlbaum Associates, Inc.

Amato, P.R. (1996). Explaining the intergenerational transmission of divorce. Journal of Marriage and the Family, 58, 628-640.

Amato, P.R., \& Booth, A. (1991). Consequences of parental divorce and marital unhappiness for adult well-being. Social Forces, 69, 895-914.

Amato, P.R., \& Booth, A. (1996). A prospective study of divorce and parent-child relationships. Journal of Marriage and the Family, 58, 356-365.

Amato, P.R., \& Booth, A. (1997). A generation at risk: Growing up in an era of family upheaval. Cambridge: Harvard University Press.

Amato, P.R., \& Cheadle, J. (2005). The long reach of divorce: Divorce and child well-being across three generations. Journal of Marriage and the Family, 67, 191-206.

Amato, P.R., Loomis, L.S., \& Booth, A. (1995). Parental divorce, marital conflict, and offspring well-being during early adulthood. Social Forces, 73, 895-915.

Amato, P.R., \& Sobolewski, J.M. (2001). The effects of divorce and marital discord on adult children’s psychological well-being. American Sociological Review, 66, 900-921.

Arnett, J.J. (2002). Emerging adulthood: A theory of development from the late teens through the twenties. In J.J. Arnett (Ed.), Readings on adolescence and emerging adulthood (pp. $17-$ 30). Upper Saddle River, NJ: Prentice Hall.

Barber, N. (1998). Sex differences in disposition towards kin, security of adult attachment, and sociosexuality as a function of parental divorce. Evolution and Behavior, 19, 125-132. 
Bartholomew, K., \& Horowitz, L.M. (1991) Attachment styles among young adults: A test of a four-category model, Journal of Personality and Social Psychology, 61, 226-244.

Bickham, N.L., \& Fiese, B.H. (1997). Extension of the children's perceptions of interparental conflict scale for use with late adolescents. Journal of Family Psychology, 11, 246-250.

Blount-Matthews, K.M. (2005). Attachment and forgiveness in human development: A multimethod approach. Dissertation Abstracts International, 66, 1753. (UMI No. 3167189)

Booth, A., \& Amato, P.R. (1994). Parental marital quality, parental divorce, and relations with parents. Journal of Marriage and the Family, 56, 21-34.

Booth, A., \& Amato, P.R. (2001). Parental predivorce relations and offspring postdivorce wellbeing. Journal of Marriage \& Family, 63, 197-212.

Bowlby, J. (1980a). Attachment and Loss (Vol. 1). New York: Basic Books, Inc.

Bowlby, J. (1980b). Attachment and Loss (Vol. 2). New York: Basic Books, Inc.

Bowlby, J. (1980c). Attachment and Loss (Vol. 3). New York: Basic Books, Inc.

Bramlett, M.D., \& Mosher, W.D. (2002) Cohabitation, Marriage, Divorce, and Remarriage in the United States. Vital Health Statistics, 23. National Center for Health Statistics.

Brennan, K.A., \& Shaver, P.R. (1993). Attachment styles and parental divorce. Journal of Divorce \& Remarriage, 21, 161-175.

Brennan, K.A., \& Shaver, P.R. (1998). Attachment styles and personality disorders: Their connections to each other and parental divorce, parental death, and perceptions of parental caregiving. Journal of Personality, 66, 835-878.

Burnette, J.L., Taylor, K.W., Worthington, E.L., Forsyth, D.R. (2007). Attachment and trait forgivingness: The mediating role of angry rumination. Personality and Individual Differences, 42, 1585-1596. 
Byrne, B.M. (2001). Structural equation modeling with AMOS: Basic concepts, applications, and programming. Mahwah: Lawrence Erlbaum Associates, Inc.

Crawley, M.J. (2006). Attachment and forgiveness as mediators between childhood abuse and self-esteem. Dissertation Abstracts International, 67, 535. (UMI No. 3202633)

Davidson, L.L. (2001). Forgiveness and attachment in college students. Dissertation Abstracts International, 61, 6129. (UMI No. 9993730)

Davies, P.T., Harold, G.T., Goeke-Morey, M.C., \& Cummings, E.M. Child Emotional Security and Interparental Conflict. Monographs of the Society for Research in Child Development, 67(3, Serial No. 270).

D'Onofrio, B.M., Turkheimer, E., Emery, R.E., Maes, H.H., Silberg, J., Eaves, L.J. (2007). A children of twins study of parental divorce and offspring psychopathology. Journal of Child Psychology \& Psychiatry, 48, 667-675.

Eldridge, R.I., \& Sutton, P.D. (2007). Births, marriages, divorces, and deaths: Provisional data for February 2007. National vital statistics reports, 56. National Center for Health Statistics.

Emery, R.E. (1999). Marriage, divorce, and children's adjustment (2nd ed.). Thousand Oakes: Sage Publications, Inc.

Erel, O., \& Burman, B. (1995). Interrelatedness of marital relations and parent-child relations: A meta-analytic review. Psychological Bulletin, 188, 108-132.

Fincham, F.D., Beach, S.R.H., Davila, J. (2004). Forgiveness and conflict resolution in marriage. Journal of Family Psychology, 18, 72-81. 
Finkel, E.J., Rusbult, C.E., Kumashiro, M., Hannon, P,A. (2002). Dealing with betrayal in close relationships: Does commitment promote forgiveness? Journal of Personality and Social Psychology, 82, 956-974.

Furman, W., \& Buhrmester, D. (1985). Children's perceptions of the personal relationships in their social networks. Developmental Psychology, 21, 1016-1024.

Grych, J.H., Seid, M., \& Fincham, F.D. (1992). Assessing marital conflict from the child's perspective: The children's perception of interparental conflict scale. Child Development, 63, 558-572.

Hanford, A.D. (2006). Attachment and forgiveness as mediators between childhood abuse and trauma symptoms. Dissertation Abstracts International, 67, 543. (UMI No. 3202634)

Hanson, T.L. (1999). Does parental conflict explain why divorce is negatively associated with child welfare? Social Forces, 77, 1283-1314.

Hayashi, G., \& Strickland, B. (1998). Long-term effects of parental divorce on love relationships: divorce as attachment disruption. Journal of Social \& Personal Relationships, 15, 23-38.

Hazan, C., \& Shaver, P. (1987). Romantic love conceptualized as an attachment process. Journal of Personality and Social Psychology, 52, 511-524.

Hazelton, R., Lancee, W., \& O’Neil, M.K. (1998). The controversial long term effects of parental divorce: The role of early attachment. Journal of Divorce \& Remarriage, 29, 117.

Hoyt, W.T., Fincham, F.D., McCullough, M.E., Maio, G., \& Davila, J. (2005). Responses to interpersonal transgressions in families: Forgivingness, forgivability, and relationshipspecific effects. Journal of Personality and Social Psychology, 89, 375-394. 
Kenny, M.E., \& Donaldson, G.A. (1991). Contributions of parental attachment and family structure to the social and psychological functioning of first-year college students. Journal of Counseling Psychology, 38, 479-486.

Kilmann, P.R., Carranza, L.V., \& Vendemia, J.M.C. (2006). Recollections of parent characteristics and attachment patterns for college women of intact vs. non-intact families. Journal of Adolescence, 29, 89-102.

Lansford, J.E., Malone, P.S. Castellino, D.R. (2006). Trajectories of internalizing, externalizing, and grades for children who have and have not experienced their parents' divorce or separation. Journal of Family Psychology, 20, 292-301.

Lawler-Row, K.A., Younger, J.W., Piferi, R.L., \& Jones, W.H. (2006). The role of adult attachment style in forgiveness following an interpersonal offense. Journal of Counseling and Development, 84, 493-502.

Lewis, M., Feiring, C., \& Rosenthal, S. (2000). Attachment over time. Child Development, 71, 707-720.

Lopez, F.G., Melendez, M.C., \& Rice, K.G. (2000). Parental divorce, parent-child bonds, and adult attachment orientations among college students: A comparison of three racial/ethnic groups. Journal of Counseling Psychology, 24, 177-186.

Luebbert, M.C. (2000). Attachment, psychosocial development, shame, guilt, and forgiveness. Dissertation Abstracts International, 60, 4234. (UMI No. 9943532)

Mack, K.Y. (2001). Childhood family disruptions and adult well-being: The differential effects of divorce and parental death. Death Studies, 25, 419-443.

Maio, G.R., Thomas, G., Fincham, F.D., Carnelley, K.B. (2008). Unraveling the role of forgiveness in family relationships. Journal of Personality and Social Psychology. 
Mann, B.J., \& Gilliom, L.A. (2004). Emotional security and cognitive appraisals mediate the relationship between parents' marital conflict and adjustment in older adolescents. Journal of Genetic Psychology, 165, 250-271.

Mikulincer, M., \& Goodman, G.S. (Eds.) (2006). Dynamics of romantic love: attachment, caregiving, and sex. New York: Guilford Press.

Mullet, E., Girard, M., \& Bakhshl, P. (2004). Conceptualizations of forgiveness. European Psychologist, 9, 78-86.

Mullet, E., Riviere, S., Munoz Sastare, M.T. (2006). Relationships between young adults' forgiveness culture and their parents' forgiveness culture. Journal of Cultural and Evolutionary Psychology, 4, 159-172.

Neal, K. L. (2006). The relationship between children's propensity to forgive, parents' propensity to forgive and parenting practices. Dissertation Abstracts International, 66, 6314. (UMI No. 3194542)

Noller, P., Feeney, J.A., \& Sheehan, G. (2000). Marital conflict patterns: Links wit family conflict and family members' perceptions of one another. Personal Relationships, 7, 7994.

Preacher, K.J., \& Hayes, A.F. (2004). SPSS and SAS procedures for estimating indirect effects in simple mediation models. Behavior Research Methods, Instruments, and Computers, 36, 717-731.

Raskin, A., Boothe, H.H., Reatig, N.A., Schulterbrandt, J.G., \& Odle, D. (1971). Factor analyses of normal and depressed patients' memories of parental behavior. Psychological Reports, 29, 871-879. 
Riggio, H.R. (2004). Parental marital conflict and divorce, parent-child relationships, social support, and relationship anxiety in adulthood. Personal Relationships, 11, 99-114.

Roberts, S.S. (2000). The effects of parental divorce on marital optimism and attachment stle in young adulthood: A path analytic model. Dissertation Abstracts International, 63, 5534. (UMI No. 3071406)

Rodrigues, L., \& Kitzmann, K. (2007). Coping as a mediator between interparental conflict and adolescents' romantic attachment. Journal of Social \& Personal Relationships, 24, 423439.

Roisman, G., Madsen, S., Hennighausen, K., Sroufe, L., \& Collins, W. (2001). The coherence of dyadic behavior across parent-child and romantic relationships as mediated by the internalized representation of experience. Attachment \& Human Development, 3, 156172.

Ross, C.E., \& Mirowsky, J. (1999). Parental divorce, life-course disruption, and adult depression. Journal of Marriage and the Family, 61, 1034-1045.

Ruschena, E., Prior, M., Sanson, A., \& Smart, D. (2005). A longitudinal study of adolescent adjustment following family transitions. Journal of Child Psychology and Psychiatry, 46, $353-363$.

Segrin, C., Taylor, M.E., \& Altman, J. (2005). Social cognitive mediators and relational outcomes associated with parental divorce. Journal of Social and Personal Relationships, 22, 361-377.

Sobolewski, J.M., \& Amato, P.R. (2007). Parents' discord and divorce, parent-child relationships, and subjective well-being in early adulthood: Is feeling close to two parents always better than feeling close to one? Social Forces, 85, 1105-1124. 
Subkoviak, M.J., Enright, R.D., Wu, C., Gassin, E.A., Freedman, S., Olson, L.M., \& Sarinopoulos, I. (1995). Measuring interpersonal forgiveness in late adolescence and middle adulthood. Journal of Adolescence, 18, 641-655.

Summers, P., Forehand, R., Armistead, L., \& Tannenbaum, L. (1998). Parental divorce during early adolescence in Caucasian families: The role of family process variables in predicting the long-term consequences for early adult psychosocial adjustment. Journal of Counseling and Clinical Psychology, 66, 327-336.

Sun, Y. (2001). Family environment and adolescents' well-being before and after parents' marital disruption: A longitudinal analysis. Journal of Marriage and the Family, 63, 697713.

Tayler, L., Parker, G., \& Roy, K. (1995) Parental divorce and its effects on the quality of intimate relationships in adulthood. Journal of Divorce \& Remarriage, 24, 181-202.

Wallerstein, J.S. (1991). The long-term effects of divorce on children: A review. Journal of the American Academy of Child and Adolescent Psychiatry, 30, 349-360.

Wade, N.G., \& Worthington, E.L. (2005). In search of a common core: A content analysis of interventions to promote forgiveness. Psychotherapy: Theory, Research, Practice, Training, 42, 160-177.

Waters, E., Merrick, S., Treboux, D., Crowell, J., \& Albersheim, L. (2000). Attachment security in infancy and adulthood: A twenty-year longitudinal study. Child Development, 27, 684689.

Webb, M., Call, S., Chickering, S.A., Colburn, T., \& Heisler, D. (2006). Dispositional forgiveness and adult attachment styles. Journal of Social Psychology, 146, 509-512. 
Table 4: Means (and standard deviations) of study variables by participant sex

\begin{tabular}{|c|c|c|c|}
\hline Sex of Participant & $\operatorname{Men}(n=84)$ & Women $(n=215)$ & $F$ \\
\hline \multicolumn{4}{|l|}{ Parent-child Relationship Quality } \\
\hline Maternal Social Support & $3.55(.67)$ & $3.86(.67)$ & $13.00 * *$ \\
\hline Maternal Neg Interaction & $2.04(.82)$ & $2.23(.86)$ & 3.16 \\
\hline Paternal Social Support & $3.21(.80)$ & $3.34(.80)$ & 1.58 \\
\hline Paternal Neg Interaction & $2.01(.85)$ & $1.93(.87)$ & .43 \\
\hline \multicolumn{4}{|l|}{ Interparental Conflict } \\
\hline Conflict Properties & $1.68(.46)$ & $1.73(.52)$ & .47 \\
\hline Threat & $1.64(.39)$ & $1.69(.48)$ & .59 \\
\hline Self-Blame & $1.32(.36)$ & $1.21(.31)$ & 6.75 \\
\hline \multicolumn{4}{|l|}{ Forgiveness } \\
\hline Participant Forgiveness & $115.30(19.31)$ & $125.15(17.88)$ & $17.54 * *$ \\
\hline Family Forgiveness & $11.92(9.27)$ & $13.92(8.94)$ & 2.99 \\
\hline \multicolumn{4}{|l|}{ Attachment } \\
\hline Secure Attachment & $3.44(.86)$ & $3.96(.66)$ & $30.41 * *$ \\
\hline Dismissing Attachment & $2.88(.82)$ & $2.34(.76)$ & $28.81 * *$ \\
\hline Preoccupied Attachment & $2.32(.74)$ & $2.34(.81)$ & .05 \\
\hline
\end{tabular}

$* * p<.001, * p<.01$ 
Table 5: Means (and standard deviations) of study variables by participant ethnicity

\begin{tabular}{clll}
\hline Ethnicity & Whites $(\mathrm{n}=271)$ & Non-Whites $(\mathrm{n}=28)$ & $F$ \\
\hline Parent-child Relationship Quality & & & \\
Maternal Social Support & $3.78(.68)$ & $3.71(.72)$ & .25 \\
Maternal Neg Interaction & $2.15(.84)$ & $2.50(.92)$ & 4.43 \\
Paternal Social Support & $3.30(.81)$ & $3.34(.70)$ & .08 \\
Paternal Neg Interaction & $1.94(.85)$ & $2.20(1.01)$ & 2.40 \\
Interparental Conflict & & & .13 \\
Conflict Properties & $1.72(.51)$ & $1.69(.45)$ & 1.31 \\
Threat & $1.67(.46)$ & $1.77(.46)$ & 6.47 \\
Self-Blame & $1.23(.31)$ & $1.39(.44)$ & .49 \\
Forgiveness & & & .38 \\
Participant Forgiveness & $122.44(19.06)$ & $119.79(19.13)$ & 1.44 \\
Family Forgiveness & $13.37(9.07)$ & $12.25(9.52)$ & .20 \\
Attachment & & $3.65(.92)$ & .82 \\
Secure Attachment & $3.83(.74)$ & $2.56(.87)$ & $2.21(.68)$ \\
Dismissing Attachment & $2.49(.81)$ & & \\
Preoccupied Attachment & $2.36(.81)$ & & \\
\hline
\end{tabular}

$* * p<.001, * p<.01$ 
Table 6: Spearman rho correlation coefficients between study variables and measures of socio-economic status

Measures of Socio-Economic Status

Maternal Education Paternal Education Difficulty Paying Bills

Parent-child Relationship Quality

Maternal Social Support

.07

.04

$-.07$

Maternal Neg Interaction

.01

.02

$.15 *$

Paternal Social Support

.15

$.22 *$

$-.27 *$

Paternal Neg Interaction

.01

.05

.11

Interparental Conflict

Conflict Properties

$-.13$

$-.10$

$.37 *$

Threat

$-.11$

$-.10$

$.32 *$

Self-Blame

$-.08$

$-.08$

.07

Forgiveness

Participant Forgiveness

.10

.05

.03

Family Forgiveness

.03

.12

$-.14$

Attachment

Secure Attachment

\begin{tabular}{ll}
$-.00 \quad .14$ \\
\hline
\end{tabular}

.01

Dismissing Attachment

.08

$-.05$

$-.02$

Preoccupied Attachment

$-.09$

$-.15$

.09

$* p<.01$ 
Table 7: Intercorrelations between predictor and outcome variables

\section{Measure}

1. Parental Divorce

2. Maternal Social

Support

3. Maternal Negative

Interaction

4. Paternal Social

Support

5. Paternal Negative

Interaction

6. Conflict Properties

7. Threat

8. Self-Blame

9. Family Forgiveness

10. Participant Forgiveness

11. Secure Attachment

12. Dismissing Attachment

13. Preoccupied Attachment $* p<.01$

$\begin{array}{lllllllllllll}1 & 2 & 3 & 4 & 5 & 6 & 7 & 8 & 9 & 10 & 11 & 12 & 13 \\ 1.00 & .04 & -.13 & .39 * & -.09 & -.48^{*} & -.40^{*} & -.08 & .16^{*} & .04 & -.04 & .07 & -.10 \\ --- & 1.00 & -.31 * & .40^{*} & .03 & -.10 & -.10 & -.31 * & .46^{*} & .20^{*} & .19^{*} & -.23 * & -.18^{*}\end{array}$

$\begin{array}{lllllllllllll}--- & -- & 1.00 & -.16^{*} & .16^{*} & .29 * & .24 * & .33^{*} & -.27^{*} & -.13 & .04 & .02 & .16^{*}\end{array}$

$\begin{array}{lllllllllllll}--- & --- & --- & 1.00 & -.25 * & -.42 * & -.38^{*} & -.11 & .40 * & .17 * & .14 & -.12 & -.09\end{array}$

$\begin{array}{llllllllllllll}--- & --- & --- & --- & 1.00 & .20 * & .20 * & .15 & -.22 * & -.05 & -.02 & .01 & -.00\end{array}$

$\begin{array}{lllllllllllll}--- & --- & --- & --- & -- & 1.00 & .78 * & .30 * & -.39 * & -.15 * & -.03 & .04 & .20 *\end{array}$

$\begin{array}{llllllllllllll}--- & -- & -- & -- & -- & -- & 1.00 & .25^{*} & -.34 * & -.17 * & -.04 & .03 & .21 *\end{array}$

$\begin{array}{lllllllllllll}--- & -- & -- & -- & -- & -- & -- & 1.00 & -.38^{*} & -.25^{*} & -.12 & .18^{*} & .26 *\end{array}$

$\begin{array}{lllllllllllll}--- & -- & -- & -- & -- & -- & --- & -- & 1.00 & .39 * & .18^{*} & -.26 * & -.32 *\end{array}$

$\begin{array}{lllllllllllll}--- & -- & -- & -- & -- & --- & -- & --- & -- & 1.00 & .18^{*} & -.29 * & -.20^{*}\end{array}$

$\begin{array}{lllllllllllll}--- & -- & -- & -- & -- & -- & -- & --- & --- & -- & 1.00 & -.75^{*} & .04\end{array}$

$\begin{array}{lllllllllllll}--- & -- & -- & -- & --- & -- & --- & --- & --- & -- & --- & 1.00 & .05\end{array}$

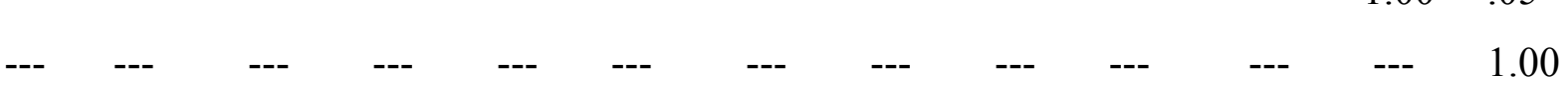


Table 8: Path coefficients for parent-child relationship quality path model

\begin{tabular}{|c|c|c|c|}
\hline Path & $B$ & S.E & $\beta$ \\
\hline Parental Divorce $\rightarrow$ Secure Attachment & -.02 & .05 & -.02 \\
\hline Parental Divorce $\rightarrow$ Dismissing Attachment & .06 & .05 & .07 \\
\hline Parental Divorce $\rightarrow$ Preoccupied Attachment & -.05 & .05 & -.06 \\
\hline Maternal Social Support $\rightarrow$ Secure Attachment & $.11 *$ & .05 & .14 \\
\hline Maternal Social Support $\rightarrow$ Dismissing Attachment & $-.13 *$ & .05 & -.16 \\
\hline Maternal Social Support $\rightarrow$ Preoccupied Attachment & -.02 & .05 & -.03 \\
\hline Maternal Neg. Interaction $\rightarrow$ Secure Attachment & .05 & .05 & .06 \\
\hline Maternal Neg. Interaction $\rightarrow$ Dismissing Attachment & -.00 & .05 & -.00 \\
\hline Maternal Neg. Interaction $\rightarrow$ Preoccupied Attachment & $.14 * *$ & .05 & .17 \\
\hline Paternal Social Support $\rightarrow$ Secure Attachment & .01 & .05 & .01 \\
\hline Paternal Social Support $\rightarrow$ Dismissing Attachment & -.03 & .06 & -.04 \\
\hline Paternal Social Support $\rightarrow$ Preoccupied Attachment & $-.16^{* *}$ & .06 & -.20 \\
\hline Paternal Neg. Interaction $\rightarrow$ Secure Attachment & -.01 & .04 & -.01 \\
\hline Paternal Neg. Interaction $\rightarrow$ Dismissing Attachment & .00 & .05 & .00 \\
\hline Paternal Neg. Interaction $\rightarrow$ Preoccupied Attachment & -.03 & .05 & -.04 \\
\hline \multicolumn{4}{|l|}{ Maternal Social Support X Parental Divorce $\rightarrow$} \\
\hline Secure Attachment & $.09 *$ & .05 & .12 \\
\hline \multicolumn{4}{|l|}{ Maternal Social Support X Parental Divorce $\rightarrow$} \\
\hline Dismissing Attachment & -.02 & .05 & -.02 \\
\hline \multicolumn{4}{|l|}{ Maternal Social Support X Parental Divorce $\rightarrow$} \\
\hline Preoccupied Attachment & $.11 *$ & .05 & .15 \\
\hline \multicolumn{4}{|l|}{ Maternal Neg. Interaction X Parental Divorce $\rightarrow$} \\
\hline Secure Attachment & $.11^{*}$ & .05 & .14 \\
\hline \multicolumn{4}{|l|}{ Maternal Neg. Interaction X Parental Divorce $\rightarrow$} \\
\hline Dismissing Attachment & -.06 & .05 & -.07 \\
\hline \multicolumn{4}{|l|}{ Maternal Neg. Interaction X Parental Divorce $\rightarrow$} \\
\hline Preoccupied Attachment & -.00 & .05 & -.00 \\
\hline \multicolumn{4}{|l|}{ Paternal Social Support X Parental Divorce $\rightarrow$} \\
\hline Secure Attachment & -.04 & .04 & -.07 \\
\hline \multicolumn{4}{|l|}{ Paternal Social Support X Parental Divorce $\rightarrow$} \\
\hline Dismissing Attachment & .04 & .05 & .06 \\
\hline \multicolumn{4}{|l|}{ Paternal Social Support X Parental Divorce $\rightarrow$} \\
\hline Preoccupied Attachment & $-.13 * *$ & .05 & -.18 \\
\hline \multicolumn{4}{|l|}{ Paternal Neg. Interaction X Parental Divorce $\rightarrow$} \\
\hline Secure Attachment & -.03 & .04 & -.05 \\
\hline
\end{tabular}


Table 8: Path coefficients for parent-child relationship quality path model

Path

$B \quad$ S.E.

Paternal Neg. Interaction X Parental Divorce $\rightarrow$ Dismissing Attachment

.04

.04

.05

Paternal Neg. Interaction X Parental Divorce $\rightarrow$

Preoccupied Attachment

Gender $\rightarrow$ Secure Attachment

Gender $\rightarrow$ Dismissing Attachment

\begin{tabular}{rrr}
.01 & .04 & .01 \\
$.64 * * *$ & .11 & -.38 \\
$.57 * * *$ & .12 & .31 \\
-.20 & .12 & -.12 \\
\hline
\end{tabular}

Gender $\rightarrow$ Preoccupied Attachment

$* * * p<.001, * * p<.01, * p<.05$ 
Table 9: Path coefficients for interparental conflict path model

Path

Parental Divorce $\rightarrow$ Secure Attachment

Parental Divorce $\rightarrow$ Dismissing Attachment

Parental Divorce $\rightarrow$ Preoccupied Attachment

Conflict Properties $\rightarrow$ Secure Attachment

Conflict Properties $\rightarrow$ Dismissing Attachment

Conflict Properties $\rightarrow$ Preoccupied Attachment

Self-Blame $\rightarrow$ Secure Attachment

Self-Blame $\rightarrow$ Dismissing Attachment

Self-Blame $\rightarrow$ Preoccupied Attachment

Threat $\rightarrow$ Secure Attachment

Threat $\rightarrow$ Dismissing Attachment

Threat $\rightarrow$ Preoccupied Attachment

Conflict Properties X Parental Divorce $\rightarrow$ Secure

Attachment

Conflict Properties X Parental Divorce $\rightarrow$ Dismissing Attachment

Conflict Properties X Parental Divorce $\rightarrow$

Preoccupied Attachment

Self-Blame X Parental Divorce $\rightarrow$ Secure Attachment

Self-Blame X Parental Divorce $\rightarrow$ Dismissing Attachment

Self-Blame X Parental Divorce $\rightarrow$ Preoccupied Attachment

Threat X Parental Divorce $\rightarrow$ Secure Attachment

Threat X Parental Divorce $\rightarrow$ Dismissing Attachment

Threat X Parental Divorce $\rightarrow$ Preoccupied Attachment

Gender $\rightarrow$ Secure Attachment

Gender $\rightarrow$ Dismissing Attachment

Gender $\rightarrow$ Preoccupied Attachment

$* * p<.01, * p<.05$

\begin{tabular}{|c|c|c|}
\hline$B$ & S.E. & $\beta$ \\
\hline --- & --- & --- \\
\hline --- & --- & --- \\
\hline --- & --- & --- \\
\hline --- & --- & --- \\
\hline --- & --- & --- \\
\hline $.15^{* *}$ & .05 & .19 \\
\hline-.05 & .05 & -.06 \\
\hline $.11^{*}$ & .05 & .13 \\
\hline $.16^{* *}$ & .05 & .20 \\
\hline --- & --- & -- \\
\hline --- & --- & --- \\
\hline--- & --- & --- \\
\hline .11 & .05 & .15 \\
\hline-.03 & .06 & -.03 \\
\hline-.03 & .06 & -.04 \\
\hline --- & --- & --- \\
\hline--- & --- & --- \\
\hline --- & --- & --- \\
\hline-.08 & .05 & -.12 \\
\hline .05 & .05 & .08 \\
\hline .09 & .05 & .14 \\
\hline $.50 * * *$ & .12 & -.29 \\
\hline $42 * * *$ & .12 & .23 \\
\hline-.16 & .12 & -.09 \\
\hline
\end{tabular}


Table 10: Path coefficients for family and participant forgiveness path model

\begin{tabular}{|c|c|c|c|}
\hline Path & $B$ & S.E. & $\beta$ \\
\hline Parental Divorce $\rightarrow$ Secure Attachment & --- & --- & --- \\
\hline Parental Divorce $\rightarrow$ Dismissing Attachment & --- & --- & --- \\
\hline Parental Divorce $\rightarrow$ Preoccupied Attachment & --- & --- & --- \\
\hline Family Forgiveness $\rightarrow$ Secure Attachment & $.11 *$ & .05 & .14 \\
\hline Family Forgiveness $\rightarrow$ Dismissing Attachment & $-.15^{*}$ & .05 & -.18 \\
\hline Family Forgiveness $\rightarrow$ Preoccupied Attachment & $-.21 * * *$ & .05 & -.27 \\
\hline Family Forgiveness $\rightarrow$ Participant Forgiveness & $.37 * * *$ & .05 & .37 \\
\hline Participant Forgiveness $\rightarrow$ Secure Attachment & .05 & .05 & .07 \\
\hline Participant Forgiveness $\rightarrow$ Dismissing Attachment & $-.15 * *$ & .05 & -.18 \\
\hline $\begin{array}{l}\text { Participant Forgiveness } \rightarrow \text { Preoccupied Attachment } \\
\text { Family Forgiveness X Parental Divorce } \rightarrow\end{array}$ & $-.10 *$ & .05 & -.13 \\
\hline Participant Forgiveness & $-.13 * *$ & .05 & -.14 \\
\hline \multicolumn{4}{|l|}{ Family Forgiveness $\mathrm{X}$ Parental Divorce $\rightarrow$} \\
\hline Secure Attachment & .05 & .04 & .07 \\
\hline \multicolumn{4}{|l|}{ Family Forgiveness $\mathrm{X}$ Parental Divorce $\rightarrow$} \\
\hline Dismissing Attachment & -.09 & .04 & -.12 \\
\hline \multicolumn{4}{|l|}{ Family Forgiveness $\mathrm{X}$ Parental Divorce $\rightarrow$} \\
\hline Preoccupied Attachment & -.03 & .04 & -.04 \\
\hline Gender $\rightarrow$ Secure Attachment & $-.46 * * *$ & .09 & -.27 \\
\hline Gender $\rightarrow$ Dismissing Attachment & $.42 * * *$ & .10 & .23 \\
\hline Gender $\rightarrow$ Preoccupied Attachment & -.12 & .10 & -.07 \\
\hline
\end{tabular}
$* * * p<.001, * * p<.01, * p<.05$ 


\begin{tabular}{|c|c|c|c|}
\hline Path & $B$ & S.E. & $\beta$ \\
\hline Maternal Social Support $\rightarrow$ Secure Attachment & .07 & .05 & .09 \\
\hline $\begin{array}{l}\text { Maternal Social Support } \rightarrow \text { Dismissing Attachment } \\
\text { Maternal Negative Interaction } \rightarrow \text { Preoccupied }\end{array}$ & -.06 & .05 & -.07 \\
\hline Attachment & .08 & .05 & .10 \\
\hline $\begin{array}{l}\text { Paternal Social Support } \rightarrow \text { Preoccupied } \\
\text { Attachment }\end{array}$ & -.05 & .05 & -.06 \\
\hline Conflict Properties $\rightarrow$ Preoccupied Attachment & .08 & .05 & .10 \\
\hline Self-Blame $\rightarrow$ Dismissing Attachment & .02 & .04 & .03 \\
\hline Self-Blame $\rightarrow$ Preoccupied Attachment & .04 & .05 & .06 \\
\hline Family Forgiveness $\rightarrow$ Secure Attachment & .09 & .05 & .12 \\
\hline Family Forgiveness $\rightarrow$ Dismissing Attachment & $-.13 *$ & .05 & -.15 \\
\hline Family Forgiveness $\rightarrow$ Preoccupied Attachment & $-.15 * *$ & .05 & -.19 \\
\hline Family Forgiveness $\rightarrow$ Participant Forgiveness & $.35 * * *$ & .05 & .35 \\
\hline Participant Forgiveness $\rightarrow$ Dismissing Attachment & $-.12 * * *$ & .03 & -.14 \\
\hline $\begin{array}{l}\text { Participant Forgiveness } \rightarrow \text { Preoccupied Attachment } \\
\text { Maternal Social Support X Parental Divorce } \rightarrow\end{array}$ & $-.09 *$ & .05 & -.12 \\
\hline $\begin{array}{l}\text { Secure Attachment } \\
\text { Maternal Social Support X Parental Divorce } \rightarrow\end{array}$ & $.10 * * *$ & .03 & .13 \\
\hline Preoccupied Attachment & $.09 *$ & .04 & .12 \\
\hline $\begin{array}{c}\text { Maternal Neg. Interaction X Parental Divorce } \rightarrow \\
\text { Secure Attachment }\end{array}$ & $.06^{*}$ & .03 & .08 \\
\hline Paternal Social Support X Parental Divorce $\rightarrow$ & & & \\
\hline $\begin{array}{l}\text { Preoccupied Attachment } \\
\text { Family Forgiveness X Parental Divorce } \rightarrow\end{array}$ & $-.11 * *$ & .04 & -.16 \\
\hline Participant Forgiveness & $-.14 * *$ & .05 & -.15 \\
\hline Family Forgiveness X Parental Divorce $\rightarrow$ & & & \\
\hline Dismissing Attachment & $-.08^{*}$ & .03 & -.10 \\
\hline Gender $\rightarrow$ Secure Attachment & $-.55 * * *$ & .09 & -.32 \\
\hline Gender $\rightarrow$ Dismissing Attachment & $.41 * * *$ & .11 & .23 \\
\hline Gender $\rightarrow$ Preoccupied Attachment & $-.23 *$ & .12 & -.16 \\
\hline Gender $\rightarrow$ Participant Forgiveness & $-.47 * *$ & .18 & -.21 \\
\hline
\end{tabular}
${ }^{* * *} p<.001,{ }^{* *} p<.01, * p<.05$ 


\section{Appendix A}

\section{Demographics}

Directions: Please answer the following questions as honestly and accurately as possible

Directions: Please answer the following questions as honestly and accurately as possible. Take care to respond to each question. There are several times when you may be prompted to respond "n/a" when a question is not applicable to you. Please do so, and do not leave any response field blank.

1. What is your age in years?

2. What is your gender?

3. Which of the following best describes your current relationship status?

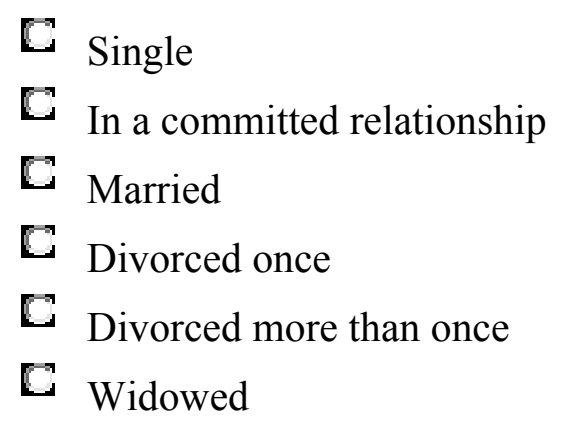

4. How long have you been in your current relationship? If you are not currently in a relationship, indicate the length in time of your most recent committed relationship. PLEASE INDICATE IN YEARS AND MONTHS (for example, " 0 years and 5 months" or " 2 years and 1 month").

5. At what age were you adopted? PLEASE INDICATE IN YEARS (for example, "3 years of age"). If you were not adopted, please respond with "not adopted".

6. Whom do you identify as your primary FEMALE parental figure while you were growing up?
C Biological mother
C Adoptive mother
C Other

7. If you responded "other female" to the last question, please indicate how you were related to or knew her (for example, "grandmother" or "neighbor"). If you DID NOT RESPOND "other female," please type "n/a" into the field below.

8. Did you ever live with the primary female parental figure you identified? 
$\begin{array}{ll}\square & \text { Yes } \\ \text { [ } & \text { No }\end{array}$

9. During what time period did you live with your primary female parental figure (for example, "from age 6 to age 10"). If you did not live with her, please respond "did not live with her".

10. Whom do you identify as your primary MALE parental figure while you were growing up?

C Biological father

C Adoptive father

C Other

11. If you responded "other male" to the last question, please indicate how you were related to or knew him (for example, "grandfather" or "neighbor"). If you DID NOT RESPOND "other male," please type "n/a" into the field below.

12. Did you ever live with the primary male parental figure you identified?

$\begin{array}{ll}\mathbb{E} & \text { Yes } \\ \boldsymbol{C}_{\mathrm{No}}\end{array}$

13. During what time period did you live with your primary male parental figure (for example, "from age 6 to age 10"). If you did not live with him, please respond "did not live with him".

14. Indicate which of the following applies to your BIOLOGICAL parents:
C Never married
C Married
C Divorced
C Mother deceased
C Father deceased
C Don't know

15. Which of the following best describes the primary parental figures that were present in your family household from birth to age 6 ?
C Biological father and mother
C Biological father only
C Biological mother only 

C Biological father and his significant other
C Biological mother and her significant other
C Adoptive father and mother
C Adoptive father only
C Adoptive mother only
C Adoptive father and his significant other
C Adoptive mother and her significant other
C Other

16. If you answered "other" to the last question, please specify the primary parental figures in your family household between birth and age 6 (for example, "my aunt and uncle"). If you DID NOT ANSWER "OTHER," please respond "n/a".

17. Please describe all divorces and/or remarriages that occurred with your parental figures between birth and age 6, making sure to indicate if you changed households (for example, "My biological mom and dad divorced. My mom remarried, my dad did not remarry, and I moved in with my dad"). If no such events took place, please respond "none".

18. Which of the following best describes the primary parental figures that were present in your family household from age 7 to age 13 ?
C Biological father and mother
C Biological father only
C Biological mother only
C Biological father and his significant other
C Biological mother and her significant other
C Adoptive father and mother
C Adoptive father only
C Adoptive mother only
C Adoptive father and his significant other
C Adoptive mother and her significant other
C Other

19. If you answered "other" to the last question, please specify the primary parental figures in your family household between age 7 and age 13. If you DID NOT ANSWER "OTHER," please respond " $\mathrm{n} / \mathrm{a}$ ". 
20. Please describe all divorces and/or remarriages that occurred with your parental figures between age 7 and age 13, making sure to indicate if you changed households (for example, "My biological mom and dad divorced. My mom remarried, my dad did not remarry, and I moved in with my dad"). If no such events took place, please respond "none".

21. How negatively affected were you by the divorce(s) that occurred during that period?

C Not negatively affected because divorce(s) DID NOT occur

C Not negatively affected, though divorce(s) DID occur

C Slightly affected in a negative way by the divorce(s)

C Moderately affected in a negative way by the divorce(s)

C Very affected in a negative way by the divorce(s)

22. Which of the following best describes the primary parental figures that were present in your family household from age 14 to age 18 ?

C Biological father and mother

C Biological father only

C Biological mother only

C Biological father and his significant other

C Biological mother and her significant other

C Adoptive father and mother

C Adoptive father only

C Adoptive mother only

C Adoptive father and his significant other

C Adoptive mother and her significant other

C Other

23. If you answered "other" to the last question, please specify the primary parental figures in your family household between age 14 and age 18. If you DID NOT ANSWER "OTHER," please respond "n/a".

24. Please describe all divorces and/or remarriages that occurred with your parental figures between age 14 and age 18, making sure to indicate if you changed households (for example, "My biological mom and dad divorced. My mom remarried, my dad did not remarry, and I moved in with my dad"). If no such events took place, please respond "none".

25. How negatively affected were you by the divorce(s) that occurred during that period? 
C Not negatively affected because divorce(s) DID NOT occur

C Not negatively affected, though divorce(s) DID occur

C Slightly affected in a negative way by the divorce(s)

C Moderately affected in a negative way by the divorce(s)

C Very affected in a negative way by the divorce(s)

26. Which of the following best describes the primary parental figures that were present in your family household from age 19 to now?
C Biological father and mother
C Biological father only
C Biological mother only
C Biological father and his significant other
C Biological mother and her significant other
$\mathbf{C}$ Adoptive father and mother
C Adoptive father only
C Adoptive mother only
C Adoptive father and his significant other
C Adoptive mother and her significant other
C Other

27. If you answered "other" to the last question, please specify the primary parental figures in your family household from age 19 until now. If you DID NOT ANSWER "OTHER" or you are under 19 years of age, please respond " $\mathrm{n} / \mathrm{a}$ ".

28. Please describe all divorces and/or remarriages that occurred with your parental figures between age 19 until now, making sure to indicate if you changed households (for example, "My biological mom and dad divorced. My mom remarried, my dad did not remarry, and I moved in with my dad"). If no such events took place, or if you are under 19 years of age, please respond "none".

29. How negatively affected were you by the divorce(s) that occurred during that period?
C Not negatively affected because divorce(s) DID NOT occur
C Not negatively affected, though divorce(s) DID occur
C Slightly affected in a negative way by the divorce(s)
C Moderately affected in a negative way by the divorce(s) 
$\mathbf{C}$ Very affected in a negative way by the divorce(s)

30. At what age did you move out of your family household?

C Still living at home

C Before 18

C $18-19$

C 19-20

C $21-22$

C 23-24

C 25 or later

31. Concerning the MALE parental figure in the household you spent most of your time in while growing up, indicate his highest level of education attained:

C No formal education

C Some high school

C Finished high school

C Some college

C Finished college

C Some graduate school

C Received Master's degree

C Received Ph.D.

32. What was his occupation?

33. Concerning the FEMALE parental figure in the household you spent most of your time in while growing up, indicate his highest level of education attained:
C No formal education
C Some high school
C Finished high school
C Some college
C Finished college
C Some graduate school
C Received Master's degree 
C Received Ph.D.

34. What was her occupation?

35. How difficult do you estimate it was to pay bills in your household while you were growing up?

C Not at all

C Somewhat (missed a few payments, but rarely)

C Very (often missed payments)

E Extremely (could rarely make all payments and had to choose what bills to pay week-toweek)

36. Please indicate the ethnicity category that best describes you:

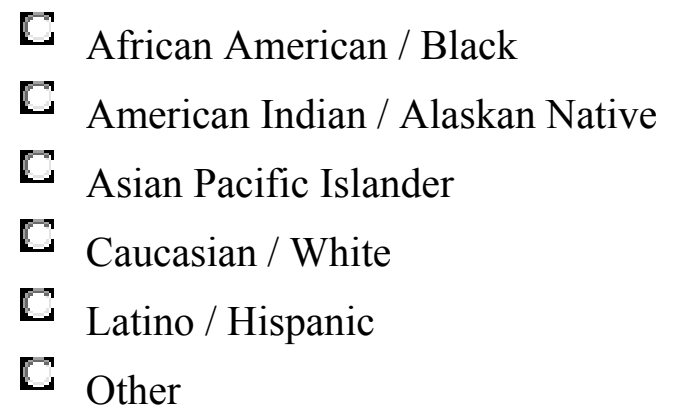

37. Please use the space below to describe any situations or events you do not feel the questions above captured regarding your parental figures or family household while you were growing up. 


\section{Appendix B}

\section{Children's Perceptions of Interparental Conflict Scale (CPICS)}

Directions: In every family, there are times when parents don't get along. When parents argue or disagree, children can feel a lot of different ways. We would like to know what kind of feelings you had when your biological parents had arguments or disagreements while you were growing up. Rate each statement as true, sort of true, or false by marking the appropriate response box below.

\begin{tabular}{|c|c|c|c|c|}
\hline \multicolumn{3}{|c|}{ Ratings } & \multirow{2}{*}{\multicolumn{2}{|c|}{ Statements }} \\
\hline True & $\begin{array}{c}\text { Sort of } \\
\text { True }\end{array}$ & False & & \\
\hline & & & 1. & I never saw my parents arguing or disagreeing \\
\hline & & & 2. & $\begin{array}{l}\text { When my parents had arguments they usually } \\
\text { worked it out }\end{array}$ \\
\hline & & & 3. & $\begin{array}{l}\text { My parents often got into arguments about things I } \\
\text { did at school }\end{array}$ \\
\hline & & & 4. & My parents got really mad when they argued \\
\hline & & & 5. & $\begin{array}{l}\text { When my parents argued I could do something to } \\
\text { make myself feel better }\end{array}$ \\
\hline & & & 6. & I got scared when my parents argued \\
\hline & & & 7. & I felt caught in the middle when my parents argued \\
\hline & & & 8. & I wasn't to blame when my parents had arguments \\
\hline & & & 9. & $\begin{array}{l}\text { They may not have though I knew it, but my parents } \\
\text { argued or disagreed a lot }\end{array}$ \\
\hline & & & 10. & $\begin{array}{l}\text { Even after my parents stopped arguing they stayed } \\
\text { mad at each other }\end{array}$ \\
\hline & & & & $\begin{array}{l}\text { My parents had arguments because they were not } \\
\text { happy together }\end{array}$ \\
\hline & & & 12. & $\begin{array}{l}\text { When my parents had disagreements they discussed } \\
\text { them quietly }\end{array}$ \\
\hline & & & & $\begin{array}{l}\text { I didn't know what to do when my parents had } \\
\text { arguments }\end{array}$ \\
\hline & & & & $\begin{array}{l}\text { My parents were often mean to each other even } \\
\text { when I was around }\end{array}$ \\
\hline & & & & $\begin{array}{l}\text { When my parents argued I worried about what } \\
\text { would happen to me }\end{array}$ \\
\hline & & & & $\begin{array}{l}\text { I didn't feel like I had to take sides when my } \\
\text { parents had disagreements }\end{array}$ \\
\hline & & & 17. & It was usually my fault when my parents argued \\
\hline & & & 18. & I often saw my parents arguing \\
\hline & & & & $\begin{array}{l}\text { When my parents disagreed about something, they } \\
\text { usually came up with a solution }\end{array}$ \\
\hline
\end{tabular}




\begin{tabular}{|c|c|c|c|c|}
\hline \multicolumn{3}{|c|}{ Ratings } & \multirow{2}{*}{\multicolumn{2}{|c|}{ Statements }} \\
\hline True & $\begin{array}{l}\text { Sort of } \\
\text { True }\end{array}$ & False & & \\
\hline & & & 20. & $\begin{array}{l}\text { My parents' arguments were usually about } \\
\text { something I did }\end{array}$ \\
\hline & & & 21. & The reasons my parents argued never changed \\
\hline & & & & $\begin{array}{l}\text { When my parents had arguments they said mean } \\
\text { things to each other }\end{array}$ \\
\hline & & & & $\begin{array}{l}\text { When my parents argued or disagreed I could } \\
\text { usually help make things better }\end{array}$ \\
\hline & & & & $\begin{array}{l}\text { When my parents argued I was afraid that } \\
\text { something bad would happen }\end{array}$ \\
\hline & & & 25. & $\begin{array}{l}\text { My mom wanted me to be on her side when she and } \\
\text { my dad argued }\end{array}$ \\
\hline & & & & $\begin{array}{l}\text { Even if they didn't say it, I knew I was to blame } \\
\text { when my parents argued }\end{array}$ \\
\hline & & & 27. & My parents hardly ever argued \\
\hline & & & & $\begin{array}{l}\text { When my parents argued they usually made up right } \\
\text { away }\end{array}$ \\
\hline & & & & $\begin{array}{l}\text { My parents usually argued or disagreed because of } \\
\text { things that I did }\end{array}$ \\
\hline & & & & $\begin{array}{l}\text { My parents argued because they didn't really love } \\
\text { each other }\end{array}$ \\
\hline & & & 31. & When my parents had an argument they yelled a lot \\
\hline & & & & $\begin{array}{l}\text { When my parents argued there was nothing I could } \\
\text { do to stop them }\end{array}$ \\
\hline & & & & $\begin{array}{l}\text { When my parents argued I worried that one of them } \\
\text { would get hurt }\end{array}$ \\
\hline & & & & $\begin{array}{l}\text { I felt like I had to take sides when my parents had } \\
\text { disagreements }\end{array}$ \\
\hline & & & & $\begin{array}{l}\text { My parents often nagged and complained about } \\
\text { each other around the house }\end{array}$ \\
\hline & & & & $\begin{array}{l}\text { My parents hardly ever yelled when they had } \\
\text { disagreements }\end{array}$ \\
\hline & & & & $\begin{array}{l}\text { My parents often got into arguments when I did } \\
\text { something wrong }\end{array}$ \\
\hline & & & & $\begin{array}{l}\text { My parents have broken or thrown things during } \\
\text { arguments. }\end{array}$ \\
\hline & & & & $\begin{array}{l}\text { After my parents stopped arguing, they were } \\
\text { friendly toward each other }\end{array}$ \\
\hline & & & & $\begin{array}{l}\text { When my parents argued I was afraid that they } \\
\text { would yell at me too }\end{array}$ \\
\hline
\end{tabular}




\begin{tabular}{|c|c|c|c|c|}
\hline \multicolumn{2}{|c|}{ Ratings } & \multicolumn{2}{c|}{ Statements } \\
\hline True & $\begin{array}{c}\text { Sort of } \\
\text { True }\end{array}$ & False & \\
\hline & & & $41 . \quad$ My parents blamed me when they had arguments \\
\hline & & & 42. & $\begin{array}{l}\text { My dad wanted me to be on his side when he and } \\
\text { my mom argued }\end{array}$ \\
\hline & & 43. & $\begin{array}{l}\text { My parents have pushed or shoved each other } \\
\text { during an argument }\end{array}$ \\
\hline & & 44. & $\begin{array}{l}\text { When my parents argued or disagreed there was } \\
\text { nothing I could do to make myself feel better }\end{array}$ \\
\hline & & 45. & $\begin{array}{l}\text { When my parents argued I worried that they might } \\
\text { get divorced }\end{array}$ \\
\hline & & 46. & $\begin{array}{l}\text { My parents still acted mean after they had an } \\
\text { argument }\end{array}$ \\
\hline & & 47. & $\begin{array}{l}\text { My parents had arguments because they didn't } \\
\text { know how to get along }\end{array}$ \\
\hline & 48. & $\begin{array}{l}\text { Usually it wasn't my fault when my parents had } \\
\text { arguments }\end{array}$ \\
\hline & $49 . \quad \begin{array}{l}\text { When my parents argued they didn't listen to } \\
\text { anything I said }\end{array}$ \\
\hline
\end{tabular}




\section{Appendix C}

Family Forgiveness Questionnaire

\begin{tabular}{|c|c|c|c|c|c|c|c|}
\hline \multicolumn{8}{|l|}{$\begin{array}{l}\text { Directions: Please indicate your level o } \\
\text { regarding your biological parents, wher } \\
\text { statement and } 3 \text { expresses that you strol }\end{array}$} \\
\hline $\begin{array}{l}\text { Generally, when I or my family } \\
\text { members annoyed, hurt, or offended } \\
\text { each other as I was growing up ... }\end{array}$ & & & & & & & \\
\hline ...we easily forgave each other. & $\begin{array}{l}\quad-3 \\
\text { strongly } \\
\text { disagree }\end{array}$ & -2 & -1 & 0 & 1 & 2 & $\begin{array}{l}3 \\
\text { strongly } \\
\text { agree }\end{array}$ \\
\hline $\begin{array}{l}\text {...we saw each other as } \\
\text { positively as we did beforehand. }\end{array}$ & $\begin{array}{l}-3 \\
\text { strongly } \\
\text { disagree }\end{array}$ & -2 & -1 & 0 & 1 & 2 & $\begin{array}{l}3 \\
\text { strongly } \\
\text { agree }\end{array}$ \\
\hline $\begin{array}{l}\text {...we held grudges against each. } \\
\text { other. }\end{array}$ & $\begin{array}{l}\quad-3 \\
\text { strongly } \\
\text { disagree }\end{array}$ & -2 & -1 & 0 & 1 & 2 & $\begin{array}{l}3 \\
\text { strongly } \\
\text { agree }\end{array}$ \\
\hline $\begin{array}{l}\text {...we saw each other more } \\
\text { negatively than we did } \\
\text { beforehand. }\end{array}$ & $\begin{array}{l}-3 \\
\text { strongly } \\
\text { disagree }\end{array}$ & -2 & -1 & 0 & 1 & 2 & $\begin{array}{l}3 \\
\text { strongly } \\
\text { agree }\end{array}$ \\
\hline $\begin{array}{l}\text {...we had difficulty forgiving } \\
\text { each other. }\end{array}$ & $\begin{array}{l}-3 \\
\text { strongly } \\
\text { disagree }\end{array}$ & -2 & -1 & 0 & 1 & 2 & $\begin{array}{l}3 \\
\text { strongly } \\
\text { agree }\end{array}$ \\
\hline $\begin{array}{l}\text {...we never really saw each other } \\
\text { as positively as before we } \\
\text { wronged each other. }\end{array}$ & $\begin{array}{l}\quad-3 \\
\text { strongly } \\
\text { disagree }\end{array}$ & -2 & -1 & 0 & 1 & 2 & $\begin{array}{l}3 \\
\text { strongly } \\
\text { agree }\end{array}$ \\
\hline $\begin{array}{l}\text {...we did not hold grudges } \\
\text { against each other. }\end{array}$ & $\begin{array}{l}\quad-3 \\
\text { strongly } \\
\text { disagree }\end{array}$ & -2 & -1 & 0 & 1 & 2 & $\begin{array}{l}3 \\
\text { strongly } \\
\text { agree }\end{array}$ \\
\hline $\begin{array}{l}\text {...we did not see each other } \\
\text { more negatively than we did } \\
\text { beforehand. }\end{array}$ & $\begin{array}{l}\quad-3 \\
\text { strongly } \\
\text { disagree }\end{array}$ & -2 & -1 & 0 & 1 & 2 & $\begin{array}{l}3 \\
\text { strongly } \\
\text { agree }\end{array}$ \\
\hline
\end{tabular}

